\title{
Collective action and the risk of ecosystem regime shifts: insights from a laboratory experiment
}

\author{
Caroline Schill $^{1,2}$, Therese Lindahl ${ }^{1,2}$ and Anne-Sophie Crépin ${ }^{1,2}$
}

\begin{abstract}
Ecosystems can undergo regime shifts that potentially lead to a substantial decrease in the availability of provisioning ecosystem services. Recent research suggests that the frequency and intensity of regime shifts increase with growing anthropogenic pressure, so understanding the underlying social-ecological dynamics is crucial, particularly in contexts where livelihoods depend heavily on local ecosystem services. In such settings, ecosystem services are often derived from common-pool resources. The limited capacity to predict regime shifts is a major challenge for common-pool resource management, as well as for systematic empirical analysis of individual and group behavior, because of the need for extensive preshift and postshift data. Unsurprisingly, current knowledge is mostly based on theoretical models. We examine behavioral group responses to a latent endogenously driven regime shift in a laboratory experiment. If the group exploited the common-pool resource beyond a certain threshold level, its renewal rate dropped drastically. To determine how the risk of such a latent shift affects resource management and collective action, we compared four experimental treatments in which groups were faced with a latent shift with different probability levels $(0.1,0.5,0.9,1.0)$. Our results suggest that different probability levels do not make people more or less likely to exploit the resource beyond its critical potential threshold. However, when the likelihood of the latent shift is certain or high, people appear more prone to agree initially on a common exploitation strategy, which in turn is a predictor for averting the latent shift. Moreover, risk appears to have a positive effect on collective action, but the magnitude of this effect is influenced by how risk and probabilities are communicated and perceived.
\end{abstract}

Key Words: common-pool resources; cooperation; ecological dynamics; laboratory experiments; regime shifts; risk; social-ecological systems; thresholds; uncertainty

\section{INTRODUCTION}

There is growing evidence that ecosystems at different scales can experience so-called regime shifts: large, abrupt, and potentially persistent changes in system structure and dynamics (Folke et al. 2004, Biggs et al. 2012). These shifts can have major impacts on bundles of produced ecosystem services crucial for human wellbeing (Millennium Ecosystem Assessment 2005, Stern 2007, Crépin et al. 2012). Moreover, recent research suggests that the frequency and intensity of ecosystem regime shifts will increase as climate change becomes more drastic and other sources of anthropogenic forces become more acute (Steffen et al. 2004, Millennium Ecosystem Assessment 2005, Rockström et al. 2009). There is growing understanding about drivers of regime shifts, their impacts on ecosystems, and how those impacts link to human well-being (see, e.g., Scheffer et al. 2001, Gordon et al. 2008, Rocha et al. 2015, and the Regime Shifts database, http:// www.regimeshifts.org, for an overview of case studies). However, empirical research on how people deal with the possibility that their actions may induce ecosystem regime shifts, affecting the flow of ecosystem services, has to our knowledge gained only little attention in the scientific literature. We examine the role of uncertainty associated with human-induced ecosystem regime shifts with a negative influence on local ecosystem service availability. We addressed the following research question: How does the risk of a latent endogenously driven undesirable ecosystem regime shift influence user group exploitation strategies (resource management) and collective action?

Regime shifts occur when the values of key ecosystem variables cross critical thresholds, either because of external pressures or endogenous processes as in this study. The critical threshold value leading from one regime to another often differs from that leading back to the initial regime. This is called hysteresis and results from the presence of internal feedback loops that maintain the new regime, making the shift difficult to reverse (Biggs et al. 2012). We conceptualize the flow of services from the local ecosystem to the resource users and the interventions of the resource users in the ecosystem, including resource use and management, as a coupled social-ecological system (Berkes and Folke 1998). Recognizing and studying these dynamic social-ecological linkages are particularly relevant in contexts in which livelihoods depend heavily on resource flow from local ecosystems and substitution opportunities are rare. In such contexts, regime shifts can threaten livelihoods (Turner et al. 2003). Provisioning ecosystem services, e.g., fish or irrigation water, are often derived from so-called common-pool resources (CPRs; Cárdenas 2009). CPRs are characterized by nonexcludability, and the resource units are subtractable; typical examples include fisheries or irrigation systems (Ostrom 1990). Therefore, we focused on a CPR management situation in which avoiding regime shifts depends on successful local collective action.

The ecosystem regime shifts considered in this study are latent and endogenously driven in the sense that only group action, i.e., overexploitation, could trigger them; and they are undesirable because of their negative influence on the availability of a commonly used and managed provisioning ecosystem service. There are many uncertainties associated with the dynamics of ecosystems, because they are complex and adaptive (Levin 1998). In general, the predictability of ecosystem dynamics is limited (Hastings and Wysham 2010). Because of hysteresis, the impact of factors influencing an ecosystem response may differ significantly at two different points in time, depending on previous events (Holling 1987, Wilson 2002). Assessing the existence of thresholds and anticipating regime shifts are often associated with large uncertainties (Scheffer et al. 2001). Techniques to detect 
regime shifts in time have recently been developed (e.g., Biggs et al. 2009, Brock and Carpenter 2012, Lade and Gross 2012, Scheffer et al. 2012), but it is unclear whether such early warning signals appear early enough to implement management actions and avoid regime shifts (Biggs et al. 2009). The ecological uncertainty can translate into risks for resource users dependent on the ecosystem. To our knowledge, current understanding of the mechanisms underlying CPR management under risk of ecosystem regime shifts stems mostly from theoretical models. Thus, this empirical study fills an important research gap.

We continued the empirical work started by Lindahl et al. (2012, 2014) on collective action in the face of latent endogenously driven ecosystem regime shifts by introducing uncertainty or more specifically, risk, because this is a typical feature of regime shifts. Lindahl et al. $(2012,2014)$ investigated experimentally how user groups in a commons dilemma respond to latent endogenously driven ecosystem regime shifts by comparing two experimental treatments, one involving a simple resource dynamic without a threshold, i.e., no threshold treatment, and the other resource dynamics with an abrupt and drastic drop in resource renewal rate beyond a critical threshold in the resource stock, i.e., threshold treatment. They found that groups facing a latent regime shift manage the CPR more efficiently than groups facing simple resource dynamics. The threat of reaching a critical threshold through their own actions appears to trigger more effective communication, i.e., making agreements, which leads to stronger commitment for cooperation, more knowledge sharing within the group, and consequently more efficient resource management.

That empirical work complements recent theoretical work in economics on CPR management in the face of ecosystem regime shifts. Mäler et al. (2003) demonstrated that the existence of latent regime shifts in lakes can complicate lake management and that noncooperation can trigger undesirable regime shifts. Crépin and Lindahl (2009) found examples where latent regime shifts could cause overexploitation or underexploitation of common grasslands. These results were derived from theoretical mathematical models and thus were based on rationality assumptions. For example, users either cooperate or they do not. When users cooperate, it is further assumed that the resource is managed optimally (so-called group rationality). When they do not cooperate, each user makes a management plan, including all possible game states, and sticks to that plan, i.e., follows an openloop Nash strategy. Theoretical studies focusing on optimal management also show that ecosystem regime shifts result in considerable management challenges (e.g., Brock and Starrett 2003, Crépin 2003, 2007). Optimal regulations may depend on past actions, and mistakes can be difficult to correct (Levin et al. 2013). However, all these contributions are based on assumptions of full knowledge of ecosystem dynamics without uncertainty.

Polasky et al. (2011) studied the impact of latent endogenously driven regime shifts on optimal management and suggested that in the presence of such shifts, and under certain conditions, an optimal management strategy would be precautionary action and reduced harvesting pressure to reduce shift probability. In commons dilemmas, however, resource users make individual management decisions and do not act as a single decision-making unit. Some experimental studies in social psychology have investigated how resource users in commons dilemmas react to uncertainty regarding resource stock size and/or regeneration rate, so-called environmental uncertainty (Messick et al. 1988). Studies focusing on resource stock size uncertainty show that experiment participants, i.e., subjects, request significantly more from the resource pool with increasing uncertainty about its size (Budescu et al. 1990, Rapoport et al. 1992, Gustafsson et al. 1999). Hine and Gifford (1996) replicated these results in a framed experiment with a group of subjects who managed a fishery over several seasons, considering also regeneration rate uncertainty. The dynamic nature of that experiment, i.e., past decisions influenced current and future conditions (path dependency), contrasts with the repeated single-trial games used by Budescu et al. and shows that the effects of environmental uncertainty can be extended to dynamic and more realistic games (Hine and Gifford 1996).

The bulk of experimental work on commons dilemmas originates from the work of Ostrom (1990) on the governance of CPRs; see Ostrom et al. (1994) on the so-called CPR baseline game. These CPR experiments are mostly performed by experimental economists and interdisciplinary researchers, and usually focus on institutional aspects (Sturm and Weimann 2006) of the dilemma, thereby ignoring potentially relevant ecosystem characteristics. A notable exception is the work of Walker and Gardner (1992), who early went beyond a static ecological environment. They extended the CPR baseline game by including path dependence, so that past choices influenced the probability of CPR destruction in the following round, to investigate how this affects resource management efficiency. They found that resource destruction prevailed, in most cases quite rapidly.

Ecological complexities have only recently been taken into account in this strand of work (Cárdenas 2009, Poteete et al. 2010) to better approximate key linkages of complex social-ecological systems (Ostrom 2009, Anderies et al. 2011). For example, Janssen et al. (2010) and Janssen (2010) introduced spatial and temporal dynamics, whereas Cardenas et al. (2013) introduced endogenously driven resource dynamics. Osés-Eraso et al. (2008) compared exogenous, i.e., environmental, and endogenous, i.e., human-induced, resource scarcity; Moreno-Sánchez and Maldonado (2010) examined contrasting resource states, i.e., abundant versus scarce; and Kimbrough and Vostroknutov (2013) determined the effects of differing resource replenishment rates. The experimental design developed by Cardenas et al. (2013) and used by Castillo et al. (2011) and Prediger et al. (2011) in different field contexts also includes spatial variability, in that subjects made two binary decisions, e.g., one about where to harvest and the other about how much to harvest. Locations with excessive harvest pressure experienced temporary resource degradation (no depletion), which is costly to reverse. Although not explicitly stated by the authors, this could be interpreted as a regime shift. Overall, these studies demonstrate unsuccessful management because the resource in both locations degraded and did not recover. In some cases, however, Prediger et al. found that groups managed the resource more carefully to avoid degradation, an effect they attributed to cultural and ecological factors the subjects face in reality. It is important to note that only three of the above-mentioned studies (Janssen 2010, Janssen et al. 2010, Moreno-Sánchez and Maldonado 2010) permitted communication in some treatments between subjects, and only the studies by 
Table 1. Experimental design.

\begin{tabular}{|c|c|c|c|c|}
\hline & $\begin{array}{l}\text { Treatment 1: } \\
\text { Threshold }^{\dagger}\end{array}$ & $\begin{array}{c}\text { Treatment } 2 \text { : } \\
\text { High risk } \\
\text { of threshold }\end{array}$ & $\begin{array}{l}\text { Treatment 3: } \\
\text { Medium risk } \\
\text { of threshold }\end{array}$ & $\begin{array}{c}\text { Treatment 4: } \\
\text { Low risk } \\
\text { of threshold }\end{array}$ \\
\hline $\begin{array}{l}\text { Probability } \\
\text { of threshold }\end{array}$ & 1.0 & 0.9 & 0.5 & 0.1 \\
\hline Description & $\begin{array}{l}\text { Subjects knew that there } \\
\text { was a threshold. }\end{array}$ & \multicolumn{3}{|c|}{$\begin{array}{l}\text { Subjects were presented with two different resource dynamics scenarios, a logistic type (A) } \\
\text { and one that entailed a threshold (B). They knew the probability of either being played. }\end{array}$} \\
\hline Number of groups ${ }^{\S}$ & $20[7 / 13]$ & $21[7 / 14]$ & $23[5 / 18]$ & $20[10 / 10]$ \\
\hline Number of subjects & 73 & 77 & 87 & 70 \\
\hline
\end{tabular}

This treatment is identical with the threshold treatment in Lindahl et al. (2012, 2014).

${ }^{*}$ This treatment is identical to the threshold uncertainty treatment in Schill (2012).

${ }^{\S}$ Numbers in squared brackets indicate number of groups with three/four subjects.

Janssen and colleagues involved stochastic resource dynamics. To our knowledge, the present study is the first to focus on the factors that enable CPR users to maintain desirable ecological conditions under the risk of latent endogenously driven ecosystem regime shifts in a setting in which communication is allowed.

To test our research question, we used a framed laboratory CPR experiment that extends the design developed by Lindahl et al. (2012). We introduced three risk treatments and compared those with the threshold treatment of Lindahl et al. This allowed us to explore group behavior in the face of a latent endogenously driven regime shift with four different probability levels: 0.1, 0.5, and 0.9 (risk treatments) and 1.0 (threshold treatment).

\section{EXPERIMENTAL SETTING}

\section{Experimental design}

Our laboratory experiment consisted of a CPR request game (see Budescu et al. 1992). Apart from its dynamic nature and the inclusion of complex ecological dynamics, i.e., threshold and hysteresis effect in resource dynamics, this game features some distinct characteristics that distinguish it from other CPR games: The framing is not neutral in that the task and information given to subjects are not abstract but rather resemble field context; i.e., the subjects are asked to harvest units of a renewable resource instead of collecting tokens (see Harrison and List 2004 for a taxonomy of experiments). Furthermore, and perhaps the most distinctive characteristic, subjects are allowed to communicate face-to-face from the start and at any time, rather than being restricted to a communication stage after the decision round. Discussions are not restricted in terms of time or content. Subjects can disclose and/or discuss their individual harvest rates and agree on a common exploitation strategy. Moreover, to approximate an infinite time horizon, the subjects do not know the exact number of rounds to be played, only that the experiment session lasts a maximum of two hours. Ostrom et al. (1994) used a similar approach. These choices stem from our intention to mimic field conditions as closely as possible. Because we intend to bring this experimental design to the field, we used pencil and paper instead of a computer-based experiment in this application (Janssen et al. 2014). For a more detailed description of the design, see Lindahl et al. (2012).
In all four experimental treatments (see Table 1 for overview), a group of subjects managed a renewable CPR. The only aspect that differed between treatments was the probability level $(0.1$, $0.5,0.9,1.0)$ with which the groups faced a threshold in the resource dynamics of the CPR. Following Schill (2012), we introduced the risk of a threshold by showing the subjects in the risk treatments the resource dynamics (using figures and tables; Appendix 1) of two different scenarios (A and B; Fig. 1a, b) and informed them that one of those scenarios was being played with a given probability. Subjects were also told that the scenario was selected ex ante by flipping a coin ( 0.5 probability treatment) or making a random draw ( 0.1 and 0.9 probability treatments). Subjects in the threshold treatment (1.0 probability) were presented only with the resource dynamics of scenario B.

Figure 1a shows the resource dynamics of scenario A, which is a discrete version of the logistic growth function. This scenario entails only smooth changes in the regeneration rate, i.e., no threshold. Scenario B includes a threshold in the resource dynamics (Fig. 1b). If the stock size decreases from one round to the other, e.g., from 20 to 19 units, the regeneration rate decreases from 7 to 1 . Because of a hysteresis effect, which we incorporated because it often occurs in regime shift dynamics, this decrease is not only drastic, but also persistent. To regain a regeneration rate of 7 units, the resource stock needs to be rebuilt to 25 units or more, i.e., the group cannot harvest anything for 5 rounds (compare the black and grey bars in Fig. 1b).

In all treatments, groups started with the maximum possible resource stock size of 50 units. Over a number of rounds, they extracted resource stock units worth SEK 5 ( $\approx$ EUR 0.50/USD $0.70)$ each.

\section{Experimental procedure}

The experiment was conducted at the Swedish Royal Academy of Sciences, Stockholm, Sweden, between May 2010 and December 2013 and involved 307 subjects recruited from the Stockholm University campus. Each subject was randomly assigned to a group of four subjects, but when only three subjects showed up, we ran the experiment anyway and tested the effect of group size. Each subject participated only once and in only one of the four treatments. They received a show-up fee of SEK $150(\approx$ EUR $16 /$ USD 22) in cash, paid privately at the end of the experiment 
Table 2. Subject pool characteristics.

\begin{tabular}{|c|c|c|c|c|}
\hline & Threshold treatment & High-risk treatment & Medium-risk treatment & Low-risk treatment \\
\hline Average group age & $28.39(1.70)$ & $25.16(0.49)$ & $25.66(0.41)$ & $25.85(0.79)$ \\
\hline Average group gender composition ${ }^{\dagger}$ & $0.63(0.07)$ & $0.35(0.06)$ & $0.39(0.05)$ & $0.5(0.06)$ \\
\hline $\begin{array}{l}\text { Average individual earnings in SEK (group } \\
\text { level) }\end{array}$ & $180.58(9.92)$ & $176.63(8.23)$ & $167.68(8.18)$ & $177.00(8.61)$ \\
\hline Nationalities ${ }^{\S}$ & \multicolumn{4}{|c|}{$\begin{array}{l}65.5 \% \text { European ( } 26 \% \text { Swedish), } 26.9 \% \text { Asians, } 5.5 \% \text { North Americans, } 1.7 \% \text { Africans, } 0.3 \% \\
\text { Australians }\end{array}$} \\
\hline Weird group index ${ }^{\dagger}$ & $0.71(0.40)$ & $0.80(0.21)$ & $0.61(0.27)$ & $0.73(0.29)$ \\
\hline
\end{tabular}

Fig. 1. Graphical illustrations of the resource dynamics of scenario A (a) and B (b) as presented to the experiment subjects. Graph (a) represents a discrete version of the logistic growth function. Graph (b) shows a resource dynamics that entails a threshold, i.e., there is a drastic and persistent drop in the regeneration rate (at a resource stock size of 20 units). In both scenarios, minimum stock size is set to 5 and maximum to 50 resource stock units. The maximum sustainable yield is set to nine units and the regeneration rate changes by steps of five units. The "hump" between 10 and 15 resource stock size units in scenario B (b) resembles a second steady state of the resource dynamics. Subjects in the threshold treatment were presented with scenario B (b) only; subjects in the risk treatments were presented with both scenarios and a probability of either scenario being played.
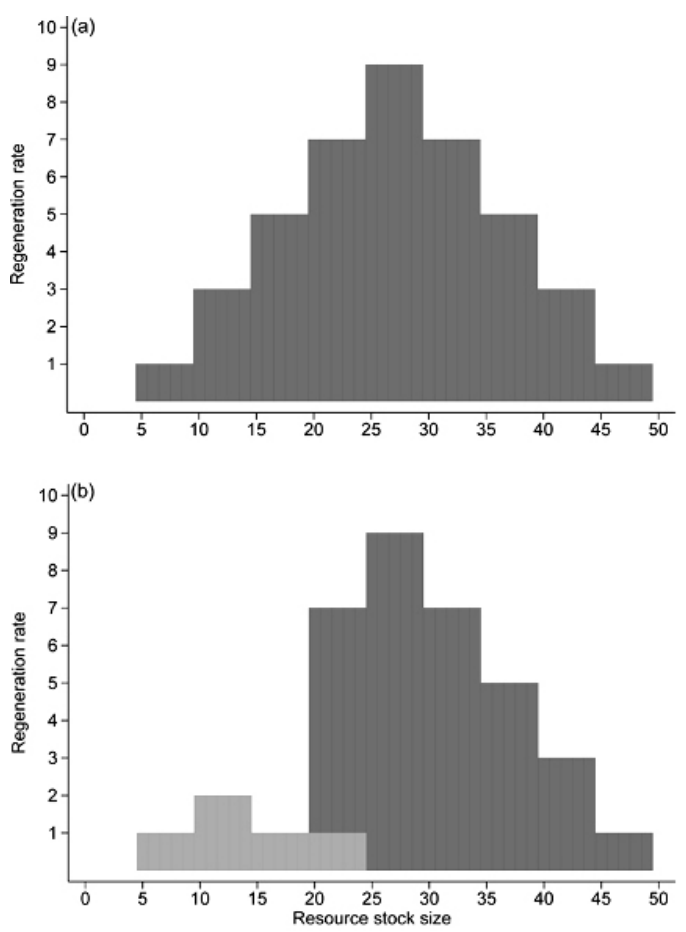

together with the individual earnings, which varied between SEK 55 and SEK 248 with a mean of SEK 176 ( $\approx$ EUR 19/USD 26). See Table 2 for average earnings per treatment and information on their significance for students in Sweden. We gathered 20 groups ( 73 subjects) for the threshold treatment, 21 groups (77 subjects) for the high-risk treatment, 23 groups ( 87 subjects) for the medium-risk treatment, and 20 groups (70 subjects) for the low-risk treatment (see Table 1). See Table 2 for general characteristics of the subject pool.

On arrival, the subjects were seated around a table, signed a consent form, were informed about what would happen in the following maximum two hours, and were given the instructions to read (see Appendix 1). Afterwards, the experimenter went through an example with the group and remaining questions were clarified.

The subjects were instructed that they each represented a fictive resource user and that they, together with other group members, had common access to a renewable resource stock. They were told that the experiment would last several rounds and that in each round they were to make an individual, private decision on how many units they would like to harvest and record that on a form (see Appendix 1). Individual decisions were anonymous in that subjects were not allowed to show each other what they had written down on the form, but because there were no restrictions with respect to communication, they could orally disclose their individual harvest rates.

After each round, the experimenter calculated the total group harvest and the new stock size to be disclosed to the group. The subjects knew that as long as there were units to harvest, the experiment would continue for a number of rounds. In that case, the experimenter stopped the group after 14 rounds. In case of resource stock depletion, which happened if the group's total harvest exceeded the available resource stock size, the game ended and the payment to each subject in that round was based on each subject's harvest share of the group's total harvest in that same round (see equation in Instructions; Appendix 1).

After the experiment, the subjects filled out a questionnaire (see Appendix 2). Apart from the usual demographic questions (age, 
gender, nationality), they were asked whether they knew someone in the group from before. They were also asked to indicate, on a five-point Likert scale (Likert 1932), to what extent they disagreed/agreed with statements about their understanding of resource dynamics and about various factors known from the literature to be relevant for cooperation in commons dilemmas. The Likert scale ranged from one (strong disagreement) to five (strong agreement). Table A3.1 in Appendix 3 lists the questionnaire variables selected. The experimenters also took notes during the course of the experiment, for example, on the exploitation strategies groups decided on or reasons for depletion.

We also ran a risk game to explore the risk preferences of our subjects. We performed 4 treatments and gathered 253 observations (see Appendix 4).

\section{Formulating hypotheses}

The outcome of this dynamic CPR game for one group was one of several alternatives. For example, the group could cooperate and maximize its joint returns, which is the optimal and most efficient outcome. Here we followed Lindahl et al. (2014) and measured efficiency as the share of actual joint earnings over the maximum possible. This optimal and efficient outcome occurred if the group harvested 25 resource stock units in the first round, and thereafter 9 units per round, corresponding to the maximum sustainable yield, as long as each group member believed that the game would continue for 1 more round with sufficiently high probability. Note that this was true for all treatments. If the stock fell below 25 units for some reason, the optimal strategy for eventually obtaining large harvests again was to let the resource recover until it reached 34 units and then to harvest 9 units in subsequent rounds (see Table A5.1 in Appendix 5 for optimal claims per stock size).

Another outcome was the other extreme, whereby the group depleted the resource entirely at some point. In between these two extremes were potential outcomes in which the group overexploited the resource and perhaps even crossed the potential threshold. In other possible outcomes, total exploitation could be less than the optimal exploitation level. Thus, we defined overexploitation, or tragedies, as exploitation above the optimal, and vice versa for underexploitation. If the group overexploited the resource to the point at which they crossed the potential threshold, the tragedy was more severe because the drop in the regeneration rate was significant and persistent. We called these two types of overexploitation modest overexploitation (stock size 20-24) and severe overexploitation (after crossing the potential threshold). Note the adjective "potential" added to the latter definition, an important distinction because we were interested in whether groups would risk crossing the potential threshold while not knowing which scenario they were actually playing. In all but the threshold treatment, the actual conditions of the experiment were revealed to the subjects on crossing the potential threshold, so that treatment uncertainty was resolved. Our main variable of interest was whether or not groups crossed the potential threshold.

Following Lindahl et al. (2014), we formulated hypotheses, based on repeated game theory methods, to guide the analysis of the results. See Appendix 6 for the underlying intuition and proofs of hypotheses.

\section{Hypothesis 1}

Hypothesis 1 was that the higher the probability of a threshold, the fewer cases of severe overexploitation. In other words, we expected fewer groups to cross the potential threshold.

If groups fully used the communication opportunity and cooperate, then it was rational for the group to follow the optimal group strategy and not cross the potential threshold, regardless of treatment. It can be debated, however, whether cooperative groups really display this type of group rationality. We defined a cooperative group as one able to reach agreement with respect to its exploitation strategy for the entire experiment and with the agreements followed by all group members, i.e., with no cheating. This implies that only groups that communicate can be classified as cooperative groups. However, it does not include whether a cooperative group actually manages the resource optimally. Furthermore, because all members of a cooperative group agreed on a common exploitation strategy, we expected inequality among the individual earnings (Gini coefficient of individual earnings) to be very low.

\section{Hypothesis 2}

Hypothesis 2 was that cooperative groups would be equally unlikely to cross the potential threshold. This hypothesis hinges on the theoretical prediction that cooperative groups follow the optimal strategy, regardless of treatment. This means that we expected cooperative groups to be equally efficient in their CPR management, regardless of treatment. Apart from this theoretical prediction, testing this hypothesis was of interest because Lindahl et al. (2014) found that cooperative groups react more or less rationally, i.e., optimally, depending on treatment, with cooperative groups facing simple resource dynamics (no threshold) being less efficient than groups facing resource dynamics with certainty about a threshold (threshold treatment, as used in this study).

The predictions we made depended on our assumptions about our subjects. Our hypotheses built on an expected utility framework, whereby subjects were assumed to behave as if they could correctly assign and interpret the probabilities associated with different relevant outcomes and could choose the action that maximized their expected utility based on these probabilities. Moreover, we assumed our subjects were risk-neutral. Assuming that our subjects were risk averse, the quantitative predictions associated with hypothesis 1 might change (see Appendix 6). However, the qualitative predictions, which were what we could and did measure, would not change. As described above, a risk game can be used to explore subjects' risk preferences.

\section{RESULTS}

The results of the risk game reveal that, depending on treatment, $71 \%-77 \%$ of subjects were neither extremely risk averse nor extremely risk seeking. Hence, there was no convincing evidence for changing the prediction of hypothesis 1 .

\section{Overall harvest patterns and face-to-face communication}

Figure 2 shows time series of resource stock size after group harvest and before growth for each group by treatment (a-d) for the first 14 rounds. The overall harvest patterns in all four treatments were relatively similar: For some rounds or the entire game, some groups underexploited the resource, i.e., resource stock size of $>25$ units; some achieved a resource stock size of 
Table 3. Comparison of proportions and averages across the four treatments for all groups and cooperative groups only.

\begin{tabular}{lllcc}
\hline \hline & $\begin{array}{l}\text { Threshold } \\
\text { treatment }\end{array}$ & $\begin{array}{l}\text { High-risk } \\
\text { treatment }\end{array}$ & $\begin{array}{c}\text { Medium-risk } \\
\text { treatment }\end{array}$ & $\begin{array}{c}\text { Low-risk } \\
\text { treatment }\end{array}$ \\
\hline
\end{tabular}

\begin{tabular}{|c|c|c|c|c|c|}
\hline \multicolumn{6}{|c|}{ All groups } \\
\hline $\mathrm{N}$ & 20 & 21 & 23 & 20 & -- \\
\hline $\begin{array}{l}\text { Proportion of crossing } \\
\text { potential threshold cases }\end{array}$ & 0.10 & 0.29 & 0.26 & 0.40 & 0.192 \\
\hline $\begin{array}{l}\text { Proportion of modest } \\
\text { overexploitation cases }\end{array}$ & 0.15 & 0.29 & 0.09 & 0.25 & 0.329 \\
\hline $\begin{array}{l}\text { Proportion of } \\
\text { depletion cases }\end{array}$ & $0.05[0]$ & $0.19[0.25]$ & $0.13[0.67]$ & $0.30[0.83]$ & 0.196 \\
\hline $\begin{array}{l}\text { Proportion of groups with } \\
\text { agreement in round one }\end{array}$ & 0.95 & 0.86 & 0.78 & 0.60 & 0.052 \\
\hline $\begin{array}{l}\text { Average Gini coefficient } \\
\text { (individual earnings) }\end{array}$ & $0.025(0.064)$ & $0.062(0.098)$ & $0.036(0.070)$ & $0.050(0.084)$ & 0.141 \\
\hline Average efficiency & $0.835(0.160)$ & $0.720(0.241)$ & $0.752(0.191)$ & $0.667(0.228)$ & 0.041 \\
\hline Average understanding & $4.513(0.457)$ & $4.389(0.547)$ & $4.265(0.642)$ & $4.388(0.361)$ & 0.517 \\
\hline \multicolumn{6}{|c|}{ Cooperative groups } \\
\hline $\mathrm{N}$ & 16 & 9 & 17 & 9 & -- \\
\hline $\begin{array}{l}\text { Proportion of } \\
\text { cooperative groups }\end{array}$ & 0.80 & 0.43 & 0.74 & 0.45 & 0.022 \\
\hline $\begin{array}{l}\text { Proportion of crossing } \\
\text { potential threshold cases }\end{array}$ & 0.00 & 0.00 & 0.06 & 0.22 & 0.180 \\
\hline $\begin{array}{l}\text { Proportion of modest } \\
\text { overexploitation cases }\end{array}$ & 0.19 & 0.33 & 0.06 & 0.22 & 0.323 \\
\hline $\begin{array}{l}\text { Proportion of cooperative } \\
\text { depletion cases }\end{array}$ & 0.00 & 0.11 & 0.06 & 0.33 & 0.051 \\
\hline $\begin{array}{l}\text { Average Gini coefficient } \\
\text { (individual earnings) }\end{array}$ & $0.003(0.003)$ & $0.007(0.015)$ & $0.004(0.004)$ & $0.007(0.015)$ & 0.888 \\
\hline Average efficiency & $0.857(0.158)$ & $0.874(0.075)$ & $0.804(0.129)$ & $0.705(0.155)$ & 0.033 \\
\hline $\begin{array}{l}\text { Average understanding } \\
\text { of resource dynamics } \$\end{array}$ & $4.578(0.397)$ & $4.537(0.334)$ & $4.368(0.458)$ & $4.602(0.291)$ & 0.464 \\
\hline
\end{tabular}

25-29 units, for which the regeneration rate was highest, in every round of the game; and a few groups moderately overexploited the resource, i.e., resource stock size of 20-24 units.

As Figure 2 also shows, some groups depleted the resource stock: one group in the threshold treatment, four in the high-risk, three in the medium-risk, and six in the low-risk treatment. Of these 14 depletion cases, 8 happened in agreement (see Table 3), a typical reason being that the group thought that the game would end soon (see Table A3.2 in Appendix 3). This result differs from that of other CPR games, in which lack of cooperation is the most usual explanation for resource stock depletion.

Although given the opportunity for face-to-face communication, subjects did not always take advantage of it. In fact, one group did not communicate at all during the whole course of the game, and another four groups did not talk in the first couple of rounds. The main topic of the communication was the common exploitation strategy. Other less frequently discussed topics were when the game might end and whether one could trust the others to act as agreed. From the forms and the experimenter notes, we could deduce that $80 \%$ of the groups agreed on a common harvest strategy in the first round; they took the opportunity to communicate and this was effective in that agreement was reached. We call this variable "group agreement round one" (see Table 3 for proportions across treatments). Note that it refers only to agreements made in the first round and that it does not imply that everyone actually followed the agreement. See Appendix 3 for the statistical analysis and all variables used.

\section{Exploitation beyond the potential threshold}

Our main variable of interest was whether groups crossed the potential threshold, i.e., severe overexploitation. We found two cases in the threshold treatment group, six cases each in the highand medium-risk treatment groups, and eight cases in the low-risk 
Fig. 2. Time series of resource stock size after group harvest and before growth for the threshold treatment (a), high-risk treatment (b), medium-risk treatment (c) and low-risk treatment (d). Data points below the red dashed line (potential threshold) indicate severe overexploitation, i.e., crossing of the potential threshold. Note that a group that crossed the potential threshold and depleted the resource stock in the same round was not classified as a group that severely overexploited the resource. Bear in mind also that these graphs do not say anything about whether the groups that crossed the potential threshold actually played scenario B. Some groups in the threshold treatment followed the exact same strategy, and this is why there appear to be fewer than 20 time series in graph (a). Four groups in graph (a) and one group in graph (d) played fewer than 14 rounds; therefore the time series stops earlier.

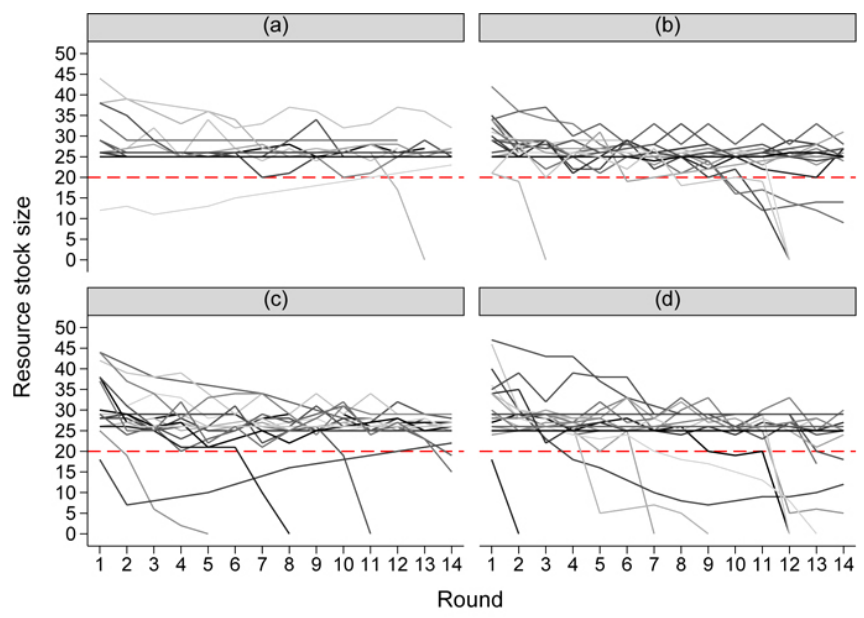

treatment group (see Fig. 2). Of the 22 groups, 10 actually played scenario $\mathrm{B}$, and 3 of these 10 groups rebuilt the resource stock to a higher regeneration rate, i.e., reversed the regime shift. To test hypothesis 1 (the higher the probability of a threshold, the fewer cases of severe overexploitation), we used a logistic regression (Maddala 1983) with severe overexploitation as the dependent variable and treatment dummies as predictors. To exclude the possibility of differences between treatments being because of treatment group characteristics other than the probability level of the threshold, we controlled for group size, age, gender, and nationality, i.e., the weird index. The weird index tests the effect of group composition in terms of subjects being from Western, educated, industrialized, rich, democratic (weird) countries (see Henrich et al. 2010; 1 = all subjects are weird). We added this control to our analysis because there is evidence that results of behavioral studies can vary considerable between "nonweird" and "weird" subjects, the latter being the standard subject pool in behavioral studies (Henrich et al. 2010). We classified European, North American, and Australian subjects as weird. Moreover, we controlled for whether groups agreed on a common harvest strategy in the first round. Table 4 shows the results, which indicate that there were no treatment effects, i.e., the number of cases of severe overexploitation did not depend on the probability level. Hence, we could reject hypothesis 1 . We also tested whether the introduction of uncertainty, i.e., risk, per se affected whether groups crossed the potential threshold by pooling the risk treatments together and comparing them with the threshold, i.e., certain, treatment. This did not change the results. We found, however, that the likelihood of crossing the potential threshold was negatively related to group agreement in round one. More specifically, the predicted probability of crossing the potential threshold for a group with an agreement in round one (given that all other predictors are set to their mean value) was only $11 \%$.

Table 4. Logistic regression results on crossing the potential threshold.

\begin{tabular}{|c|c|c|}
\hline \multirow[t]{2}{*}{ Variable } & \multicolumn{2}{|c|}{ Crossing potential threshold } \\
\hline & Coef. & (Std. err.) \\
\hline Constant & 0.043 & $(2.725)$ \\
\hline High-risk treatment & 1.456 & $(1.159)$ \\
\hline Medium-risk treatment & 1.173 & (1.092) \\
\hline Low-risk treatment & 0.721 & (1.069) \\
\hline Group agreement round one & $-3.340 * * *$ & $(0.841)$ \\
\hline Group of 4 subjects & -1.008 & $(0.662)$ \\
\hline Average age & -0.011 & $(0.086)$ \\
\hline Gender composition $^{\dagger}$ & 1.429 & $(1.306)$ \\
\hline Weird index ${ }^{\dagger}$ & 0.922 & $(1.286)$ \\
\hline LR $x^{2}$ & $31.27 * * *$ & \\
\hline Pseudo $\mathrm{R}^{2}$ & 0.324 & \\
\hline $\mathrm{N}$ & 84 & \\
\hline \multicolumn{3}{|c|}{$\begin{array}{l}\text { Note: The dependent variable crossing potential threshold (severe } \\
\text { overexploitation) is a binary variable (value } 1 \text { denotes that group } \\
\text { crossed the potential threshold). See Table A3.1 in Appendix } 3 \text { for a } \\
\text { description of the variables used. } \\
\text { These variables are dichotomous on individual level (female }=1 \text {; } \\
\text { weird }=1 \text { ). } \\
* * * p<0.01 ; * \mathrm{p}<0.05 ; *^{*}<0.1 \text {. }\end{array}$} \\
\hline
\end{tabular}

As Figure 3 shows, there were 9 cooperative groups in the lowrisk, 17 in the medium-risk, 9 in the high-risk, and 16 in the threshold treatment (see Table 3 for relative proportions). These cooperative groups (note that they are endogenously determined) achieved an even distribution of earnings by following one or a mix of the following approaches: (1) equal individual harvests in each round or (2) a rotating scheme to keep the total individual earnings equal (see Table A3.2 for group-specific information). As expected, there was no significant difference with respect to the Gini coefficient in individual earnings of the group members. To test hypothesis 2, we compared cases of severe overexploitation among cooperative groups in the four treatments. As Figure 3 shows, in the threshold and high-risk treatments, none of the cooperative groups crossed the potential threshold, in the medium-risk treatment there was one, and in the low-risk treatment two (see Table 3 for proportions). We found that as expected, cooperative groups were equally unlikely to cross the potential threshold (using Fisher's exact test), independent of treatment. Hence, we were unable to reject hypothesis 2 . Please note that when cooperative groups crossed the potential threshold, this happened in agreement, as for cooperative depletion. This, in addition to our theoretical results, provides evidence that cooperation can be seen as a necessary but not sufficient condition for sustainable resource management in our setting. 
Fig. 3. Time series of resource stock size after group harvest and before growth for each cooperative group of the threshold treatment (a) with $\mathrm{N}=16$, high-risk treatment (b) with $\mathrm{N}=9$, medium-risk treatment (c) with $\mathrm{N}=17$, and low-risk treatment (d) with $\mathrm{N}=9$. Data points below the red dashed line (potential threshold) indicate severe overexploitation, i.e., crossing of the potential threshold. Note that a group that crossed the potential threshold and depleted the resource stock in the same round was not classified as a group that severely overexploited the resource; this applies only to one group in graph (d). Bear in mind also that these graphs do not say anything about whether the groups that crossed the potential threshold actually played scenario B. Three groups in graph (a) played fewer than 14 rounds and therefore the time series stopped earlier.

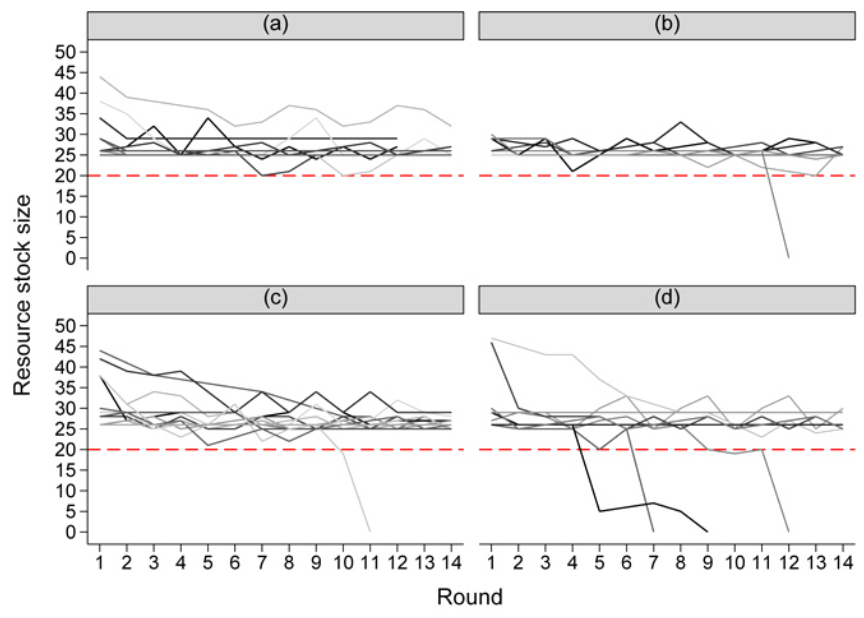

\section{Evaluating efficiency}

On comparing the average efficiency achieved between all four treatments, we found significant differences (Kruskal-Wallis test, $p=0.041$, which are only because of a significant difference between the threshold and low-risk treatments (with Bonferroni correction, $p=0.073$ ). Table 3 shows exact values and Figure 4a compares average efficiency achieved over time, including all groups. Considering cooperative groups only, we again found significant differences (Kruskal-Wallis test, $p=0.031$ ). This contradicted our expectations regarding group rationality. Thus, although there were no differences between cooperative groups with respect to crossing the potential threshold, they were not equally efficient in resource management. The significant differences in this case were also because of a significant difference between groups in the threshold and low-risk treatments, the latter being significantly less efficient. In addition, this difference also emerged between the low-risk and high-risk treatments. The average efficiency achieved was higher for cooperative groups in all treatments (Fig. 4b), with the most distinct increase in the highrisk treatment (from 0.720 to 0.874 ; Table 3 ). Note that we found no differences between the treatments, considering all groups and only cooperative groups, regarding understanding of resource dynamics in self-reported values from the postexperimental questionnaire (see Table 3).

Figure 3 offers some clues that the higher overall efficiency achieved by the high-risk treatment groups compared with the low-risk groups appears not to have been because of less overexploitation, but to less underexploitation. A Pearson's chisquare test confirmed this: comparing cases of resource stock size after harvest above 29 resource stock units, cooperative groups in the low-risk treatment underexploited the resource significantly more than cooperative groups in the high-risk treatment $(p=$ 0.000 ). This indicates that the efficiency measure should be used with care in this case, because it masks some effects by not allowing differentiation between underexploitation and overexploitation. In particular, the latter could lead to a disastrous regime shift, while underexploitation does not. Moreover, for the risk treatments, the efficiency measure also included rounds after the uncertainty resolution; hence, any actions taken by the subjects after this resolution were difficult to interpret. For those reasons, our main variable of interest was whether the groups crossed the potential threshold.

Fig. 4. Comparison of average efficiency achieved given the current resource stock size over time between all four treatments for all groups (a) $(\mathrm{N}=20$ for threshold treatment; $\mathrm{N}$ $=21$ for high-risk treatment; $\mathrm{N}=23$ for medium-risk treatment; $\mathrm{N}=20$ for low-risk treatment) and for cooperative groups only (b) ( $\mathrm{N}=16$ for threshold treatment; $\mathrm{N}=9$ for high-risk treatment; $N=17$ for medium-risk treatment; $N=9$ for low-risk treatment).

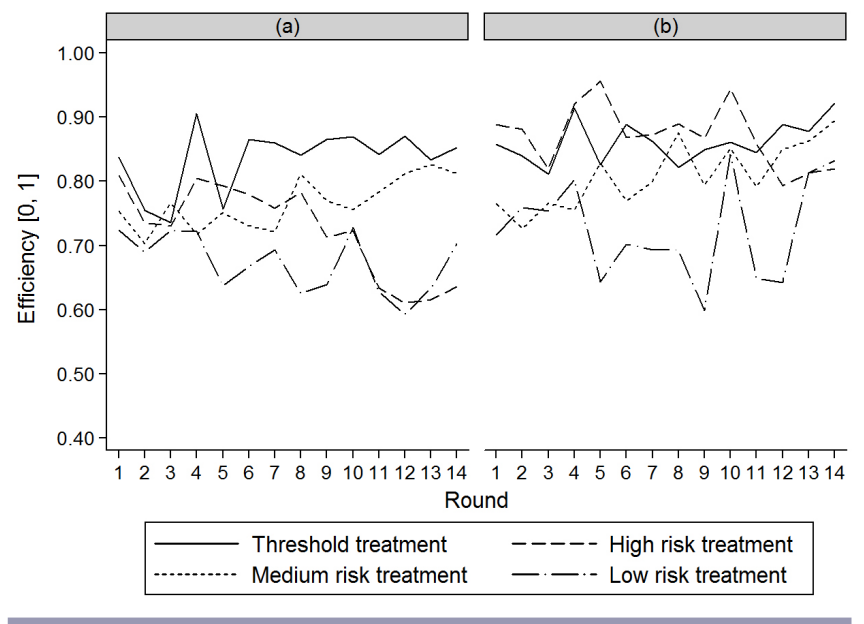

Exploring predictors for avoiding regime shifts

Many previous studies show that cooperation has a positive effect on sustainable resource management, and we are able to confirm this. Figure 5 compares the average resource stock size after harvest for cooperative groups (b) and the remaining noncooperative groups (a). It is clearly apparent that cooperative groups maintained, on average, a resource stock size above the potential threshold, in contrast to noncooperative groups. A Pearson's chi-square test confirmed that only cooperative groups refrained from crossing the potential threshold $(p=0.000)$. Moreover, the logistic regression used to test hypothesis 1 indicated that group agreement in round one significantly decreased the likelihood of crossing a potential threshold. Therefore, we explored predictors for initial communication and for cooperation, both of which were endogenously determined. We conducted two logistic regressions, each using a different dependent variable: group agreement round one, model (1) in 
Table 5. Logistic regression results of group agreement in round one and cooperative group.

\begin{tabular}{|c|c|c|c|c|}
\hline Variable & $\begin{array}{l}\text { Model (1a) - } \\
\text { Group agreement round } \\
\text { one }\end{array}$ & $\begin{array}{l}\text { Model }(1 \mathrm{~b}) \text { - } \\
\text { Group agreement round } \\
\text { one }\end{array}$ & $\begin{array}{l}\text { Model }(2 \mathrm{a})- \\
\text { Cooperative } \\
\text { group }\end{array}$ & $\begin{array}{l}\text { Model }(2 b)- \\
\text { Cooperative } \\
\text { group }\end{array}$ \\
\hline & Coef. (std. err.) & Coef. (std. err.) & Coef. (std. err.) & Coef. (std. err.) \\
\hline Constant & $-0.601(2.227)$ & $-0.975(0.775)$ & $-1.044(1.859)$ & $-1.103(1.746)$ \\
\hline High-risk treatment & $1.512 *(0.872)$ & $1.688 * *(0.851)$ & $-0.078(0.672)$ & $-0.101(0.641)$ \\
\hline Medium-risk treatment & $0.984(0.767)$ & $0.908(0.748)$ & $1.151 *(0.681)$ & $1.164 *(0.671)$ \\
\hline Threshold treatment & $2.665 * *(1.275)$ & $2.357 * *(1.152)$ & $1.357 *(0.757)$ & $1.369 *(0.743)$ \\
\hline Know others from before & $0.581(1.094)$ & & $0.783(0.785)$ & $0.798(0.784)$ \\
\hline Group of 4 subjects & $0.916(0.626)$ & $0.858(0.614)$ & $0.174(0.513)$ & $0.185(0.509)$ \\
\hline Average age & $-0.045(0.079)$ & & $0.028(0.065)$ & $0.025(0.063)$ \\
\hline Gender composition $^{\dagger}$ & $1.640(1.222)$ & $1.997 *(1.178)$ & $0.034(0.961)$ & \\
\hline Weird index ${ }^{\dagger}$ & $1.121(1.197)$ & & $-0.189(0.915)$ & \\
\hline $\operatorname{LR} \chi^{2}$ & $15.10^{*}$ & $13.93 * *$ & 11.35 & $11.31 *$ \\
\hline Pseudo $\mathrm{R}^{2}$ & 0.178 & 0.165 & 0.101 & 0.1005 \\
\hline $\mathrm{N}$ & 84 & 84 & 84 & 84 \\
\hline
\end{tabular}

Note: The dependent variables group agreement round one and cooperative group are binary variables (value 1 denotes that a group made an agreement in round one or was classified as a cooperative group). According to a likelihood ratio test, the reduced models (1b) and ( $2 \mathrm{~b}$ ) lead to significantly better fit (test results for Model (1): LR $\chi^{2}=1.17, p=0.76$; Model (2): LR $\chi^{2}=0.04, p=0.98$ ). See Table A3.1 in Appendix 3 for a description of the variables used. Other model specifications are available upon request.

${ }^{\dagger}$ These variables are dichotomous on individual level (female $=1$; weird $=1$ ).

$* * * \mathrm{p}<0.01 ; * * \mathrm{p}<0.05 ;{ }^{*} \mathrm{p}<0.1$

Fig. 5. Comparison of average resource stock size after harvest over time between all four treatments for noncooperative groups (a) ( $\mathrm{N}=4$ for threshold treatment; $\mathrm{N}=11$ for high-risk treatment; $\mathrm{N}=6$ for medium-risk treatment; $\mathrm{N}=10$ for lowrisk treatment) and cooperative groups (b) $(\mathrm{N}=16$ for threshold treatment; $\mathrm{N}=9$ for high-risk treatment; $\mathrm{N}=17$ for medium-risk treatment; $\mathrm{N}=9$ for low-risk treatment). Data points below the red dashed line (potential threshold) indicate severe overexploitation. Data points between a resource stock size of 25 and 29 units indicate that in those rounds the groups achieved on average a regeneration rate of 9 units, the highest possible.

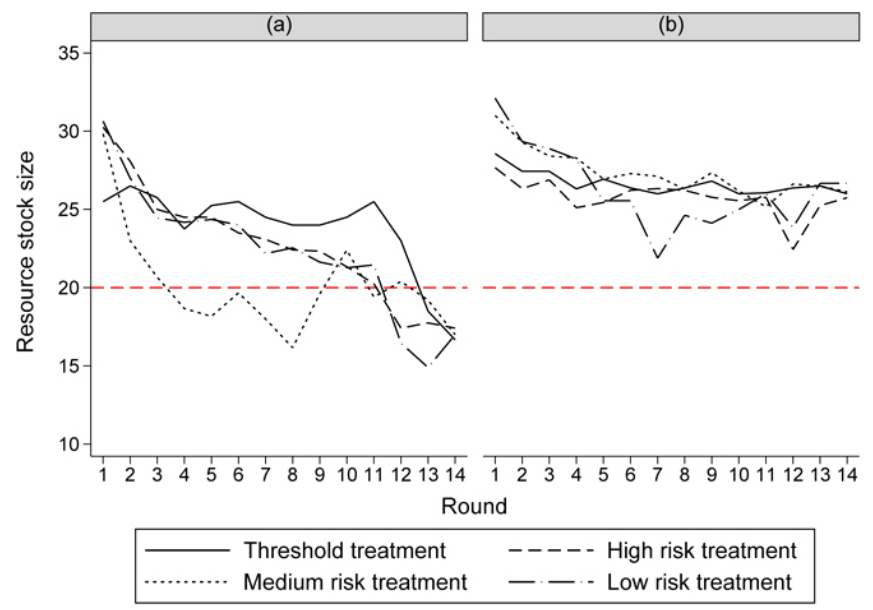

Table 5; and cooperative group, model (2) in Table 5. In addition to treatment dummies, we included a dummy for group size and variables to control for age, gender, and nationality (weird index) in the groups. We also controlled for whether subjects knew each other before the experiment, because this could have influenced initiating communication and cooperation in particular, because of the specific communication design. As model (1b) in Table 5 shows, the odds of group agreement in round one are positively related to the threshold and high-risk treatment and to groups with a higher proportion of females. These results suggest that the threshold and high-risk treatments and gender composition were not good controls for the first regression we used, in which crossing the potential threshold was the dependent variable. See the Results section on exploitation beyond the potential threshold. We ran a two-stage logistic regression in which we used the predicted values from the model (1) regression in the first regression (crossing potential threshold). We found that group agreement in round one was still significant, suggesting that the threshold and high-risk treatments, as well as gender composition, had an indirect effect on whether or not groups crossed the potential threshold. As Model (2b) in Table 5 shows, the odds for cooperative groups were positively related to the threshold and medium-risk treatments.

\section{DISCUSSION}

Abundant empirical evidence (e.g., Tversky and Kahneman 1974) suggests that in complex and uncertain decision problems, as in our experiment, the assumptions that underlie expected utility theory are highly questionable. In such situations, decision makers typically violate the principles of expected utility maximization and rely instead on shortcuts or heuristics, which are sometimes systematically biased (Tversky and Kahneman 1974). Empirical cognitive research suggests that people generally have problems with interpreting probabilities. For example, people tend to systematically overweight small probabilities and underweight large and moderate probabilities (Kahneman and Tversky 1979, Tversky and Kahneman 1992). Such a bias can explain why we observed no distinct difference between the low-risk and high-risk 
treatments regarding severe overexploitation, in contrast to our theoretical predictions and the number of cooperative groups. Another potential explanation could, of course, be our particular face-to-face communication design. We allowed communication at all stages of the game, and subjects were seated around a table and could look into each other's faces. We found that once a group made a decision on a common harvest strategy and followed it for a few rounds, individuals would not break this group agreement easily. Hence, we should perhaps not be surprised to find no distinctive difference between the high-risk and low-risk treatments regarding severe overexploitation and cooperative groups. This design feature might also explain the large number of cooperative groups we found in general, across all four treatments.

However, our particular face-to-face communication design cannot explain why the medium-risk treatment (0.5) outperformed the high-risk treatment $(0.9)$ with more cooperative groups. Another common bias could explain why the mediumrisk treatment stood out: people tend to judge probabilities by the ease of association to relevant examples. This is referred to as "availability" (Tversky and Kahneman 1973) and may explain why disproportionately high weight is assigned to more easily remembered information. Recall that in the medium-risk treatment, the probability of a threshold was described as flipping a coin, a procedure with which most people are familiar, can relate to, and can use as a reference when assigning a probability weight. A 50/50 chance of a threshold can then be viewed as very likely. In comparison, a probability of 0.9 (or 0.1 ) is much harder to relate to and to assign an accurate probability weight to.

We found no differences between the high-risk and low-risk treatments regarding the number of cooperative groups. However, there were differences in efficiency; i.e., group rationality did not hold. This was not because the low-risk treatment induced more overexploitation, although that would be expected because deviations from the optimal strategy in the direction of overharvesting were more costly in the high-risk treatment. Instead, cooperative groups in the high-risk treatment underexploited the resource significantly less than groups in the low-risk treatment. They anchored their decisions on the very likely threshold; i.e., they coordinated around the strategy of not crossing the potential threshold, making them more efficient. This (perhaps counterintuitive) result also indicates that efficiency might not be a good measurement for resource management when the possibility of an endogenously driven disastrous regime shift exists. Our results indicate that under certain conditions, i.e., cooperation and high risk, a threshold can serve as a focal point that helps people coordinate and thereby protect ecological functions they depend on. This suggests that it may be fruitful to further study how to exploit people's tendency to simplify complex problems and coordinate around a solution that seems easy to achieve (see Schelling 1960 on focal points). If the threshold is not known, a potential policy intervention could be to use safe minimum standards (Ciriacy-Wantrup 1952) as a signaling device.

Several experimental studies (e.g., Messick et al. 1988, Budescu et al. 1990) have shown that introducing environmental uncertainty in commons dilemmas leads to more cases of overexploitation. Our results contradict this finding. Those studies on environmental uncertainty and the studies that introduced endogenously driven resource dynamics (e.g., Prediger et al. 2011, Cardenas et al. 2013) did not permit communication. Previous CPR research shows that face-to-face communication per se is important for determining whether groups will cooperate or not (e.g., Pretty 2003, Ostrom 2006). There is also considerable empirical evidence in the experimental literature of the positive effect of communication on cooperation (e.g., Sally 1995 and Balliet 2009 for literature reviews). Lindahl et al. (2014) showed that the effectiveness of communication (making group agreements), which underlies cooperation, can be endogenous to the decision problem. We can support this finding, because there were differences across the four treatments in making group agreements in the first round and in cooperation, for which effective communication is a necessary condition. Lindahl et al. (2014) could not identify the triggers of effective communication, whether it is the latent regime shift that people perceive as a threat or the complex decision problem. Our results support the threat hypothesis. Indeed, although the level of complexity was similar in all risk treatments, we found that significantly more groups in the threshold and high-risk treatments than in the medium- and low-risk treatments made an agreement in the first round; in the latter two, the risk, i.e., the threat of a latent regime shift, was lower. A potential regime shift is clearly associated with potential welfare losses and can be seen as a threat.

We focused solely on risk situations; i.e., all the possible outcomes and their probability distribution are known. This setting could describe real situations for well-studied ecosystems in which the probability of a regime shift occurring in the future can be roughly extrapolated from past behavior in similar systems. However, many real-life situations are not so clear. For example, one can usually only predict a range where the system might shift (Biggs et al. 2012), and often one cannot determine whether a system has possible alternate regimes and what these might be. Coral reefs, which are relatively well studied in this respect, can even have more than two different regimes (Norström et al. 2009). This profound lack of information about ecosystems calls for further studies on behavior regarding different aspects of environmental uncertainty. A natural extension of this study would be to test the impacts of uncertain threshold location. An experimental study by Barrett and Dannenberg (2012) on a threshold public-good game showed that uncertainty about the location of the threshold, when huge welfare losses were at stake, significantly decreased contribution levels. However, they used a one-shot game. Future research could also study people's behavior toward surprise, e.g., an unexpected drop in resource renewal rate, uncertainty about the size of the hysteresis, or other ecological features. For policy purposes, it might be relevant to explore whether, and how, the nonstandard motivations (biases) mentioned above play out in our experimental design. For example, we could extend the design to test the effect of how probabilities are presented to the subjects by using a 10 -sided dice instead of a draw to determine the lowand high-risk treatment scenarios. We believe that rolling a dice is easier to understand and could therefore diminish the availability bias, which we hypothesized could be a potential cause of our counterintuitive results; e.g., medium risk produced more cooperation than high risk.

We want to highlight that our results stem from laboratory experiments with students as subjects and as such we should be 
cautious when we generalize the findings. One criticism relates to the fact that the typical subjects of laboratory experiments represent only a very restricted sample of humanity; i.e., they can be called "weird" (see the Results section and Henrich et al. 2010). However, our subject pool was relatively diverse; about a third of our subjects came from a "nonweird" country. We did not find, however, that the weird index had an effect and that might be because a "nonweird" student coming to Sweden to study may in fact have a background similar to that of a "weird" student, which may render our control unsatisfactory. To increase confidence in our results, a natural next step would be to take this design to the field. As Harrison and List (2004) point out, to extrapolate experimental findings beyond the laboratory, it is necessary to perform several types of experiments.

\section{CONCLUSIONS}

In this experimental study, we explored how groups deal with different probability levels regarding a latent endogenously driven ecosystem regime shift that negatively and persistently affects the availability of a commonly shared resource. We found that whether or not people face such a latent shift with certainty or different risk levels (low, medium, high) does not make them more or less likely to exploit the resource beyond its critical potential threshold. However, if the likelihood of the latent shift was certain or high and if there were more females in the group, groups were more prone to initially agree on a common exploitation strategy, which in turn increased the likelihood of averting the latent shift. Furthermore, we found that cooperative groups are equally unlikely to cross the potential threshold. The risk level also influenced how efficient the groups were in managing the resource and whether or not groups cooperated. Cooperative groups facing a threshold with certainty or a $90 \%$ chance performed better, generating higher payoffs and managing the resource more sustainably. Threshold certainty and a 50/50 chance of being confronted with a threshold also increased the likelihood of cooperation. We attributed this outcome, i.e., medium risk produced more cooperation than high risk, to possible different behavioral responses to the two ways used to present the probabilities in the game, i.e., lottery versus flipping a coin. Hence, risk influenced individual and group behavior in our CPR setting and triggered certain behaviors, but the exact levels of risk that triggered a particular behavioral response (group agreement in round one and cooperation) were ambiguous and need further exploration.

Based on the results, some recommendations can be made on how to support decision making for vulnerable populations whose actions could trigger ecosystem regime shifts that negatively affect the basis for their livelihoods. First, the potential for such undesirable regime shifts should be communicated, especially in situations when the actual risk is high or certain, because we found that such situations increase the likelihood of user groups engaging early in decision making on how to manage the CPR, which in turn is a predictor for averting an undesirable regime shift. Second, long-term collective action should be promoted, because it is likely to prevent latent regime shifts and also enables more sustainable resource management in social-ecological terms. Finally, rather than assessing accurate risk levels, clear thought is needed about how to communicate risks. We found that people may have difficulties in grasping probabilities other than a 50/50 chance, which they can easily visualize, e.g., flipping a coin. In a nutshell, the risk level, how it is communicated, and collective action play a role in preventing human activities like resource extraction from pushing an ecosystem into an undesirable state.

Responses to this article can be read online at: http://www.ecologyandsociety.org/issues/responses. $\mathrm{php} / 7318$

\section{Acknowledgments:}

We are thankful for financial support from the EU FP7 Arctic Tipping Point (ATP) project (contract \#226248), the EU FP7 ACCESS project contract \#265863) under the call Ocean of Tomorrow, FORMAS SUPER-project (\# 250-2010-145), the Ebba and Sven Schwartz Foundation, the Stockholm Resilience Centre, and the Kjell and Märta Beijer Foundation. We gratefully acknowledge comments received from three anonymous reviewers, the guest editor of this special feature, and seminar participants at the following conferences, workshops, and seminars: CSID workshop, University of Arizona, Tempe, Arizona, USA (March 2013); 20th EAERE conference, Toulouse, France (June 2013); 20th Ulvön conference, Ulvön, Sweden (June 2013); seminar at the Department of Economics, Umeå University, Umeå, Sweden (October 2013); and WOW5, Indiana University, Bloomington, Indiana, USA (June 2014). We thank Johanna Drie, Nikolina Oreskovic, and Britt Stikvoort for experiment assistance and Daniel Ospina-Medina, Matías Piaggio, and Chandra Kiran for valuable discussions. Last but not least, we would like to thank our experiment participants. Part of this study was initiated as the first author's Master's thesis (Schill 2012).

\section{LITERATURE CITED}

Anderies, J. M., M. A. Janssen, F. Bousquet, J.-C. Cardenas, D. Castillo, M.-C. Lopez, R. Tobias, B. Vollan, and A. Wutich. 2011. The challenge of understanding decisions in experimental studies of common pool resource governance. Ecological Economics 70:1571-1579. http://dx.doi.org/10.1016/j.ecolecon.2011.01.011

Balliet, D. 2009. Communication and cooperation in social dilemmas: a meta-analytic review. Journal of Conflict Resolution 54:39-57. http://dx.doi.org/10.1177/0022002709352443

Barrett, S., and A. Dannenberg. 2012. Climate negotiations under scientific uncertainty. Proceedings of the National Academy of Sciences of the United States of America 109:17372-17376. http:// dx.doi.org/10.1073/pnas. 1208417109

Berkes, F., and C. Folke. 1998. Linking social and ecological systems: management practices and social mechanisms for building resilience. Cambridge Univeristy Press, Cambridge, UK.

Biggs, R., T. Blenckner, C. Folke, L. Gordon, A. Norström, M. Nyström, and G. D. Peterson. 2012. Regime shifts. Pages 1-19 in A. Hastings and L. Gross, editors. Sourcebook in theoretical ecology. University of California Press, Berkeley, California, USA.

Biggs, R., S. R. Carpenter, and W. A. Brock. 2009. Turning back from the brink: detecting an impending regime shift in time to avert it. Proceedings of the National Academy of Sciences of the 
United States of America 106:826-831. http://dx.doi.org/10.1073/ pnas.0811729106

Brock, W. A., and S. R. Carpenter. 2012. Early warnings of regime shift when the ecosystem structure is unknown. PLoS ONE 7(9): e45586. http://dx.doi.org/10.1371/journal.pone.0045586

Brock, W. A., and D. Starrett. 2003. Managing systems with nonconvex positive feedback. Environmental and Resource Economics 26:575-602. http://dx.doi.org/10.1023/B:EARE.0000007350.11040. e3

Budescu, D. V., A. Rapoport, and R. Suleiman. 1990. Resource dilemmas with environmental uncertainty and asymetric players. European Journal of Social Psychology 20:475-487. http://dx.doi. org/10.1002/ejsp.2420200603

Cárdenas, J. C. 2009. Experiments in environment and development. Annual Review of Resource Economics 1:157-182. http://dx.doi.org/10.1146/annurev.resource.050708.144056

Cardenas, J.-C., M. A. Janssen, and F. Bousquet. 2013. Dynamics of rules and resources: three new field experiments on water, forests and fisheries. Pages 319-345 in J. A. List and M. K. Price, editors. Handbook on experimental economics and the environment. Edward Elgar, Cheltenham, UK. http://dx.doi. org/10.4337/9781781009079.00020

Castillo, D., F. Bousquet, M. A. Janssen, K. Worrapimphong, and J. C. Cardenas. 2011. Context matters to explain field experiments: results from Colombian and Thai fishing villages. Ecological Economics 70:1609-1620. http://dx.doi.org/10.1016/j. ecolecon.2011.05.011

Ciriacy-Wantrup, S. V. 1952. Resource conservation. University of California Press, Berkeley, California, USA.

Crépin, A.-S. 2003. Multiple species boreal forests-what Faustmann missed. Environmental and Resource Economics 26:625-646. http://dx.doi.org/10.1023/B:EARE.0000007352.02799.0e

Crépin, A.-S. 2007. Using fast and slow processes to manage resources with thresholds. Environmental and Resource Economics 36:191-213. http://dx.doi.org/10.1007/s10640-006-9029-8

Crépin, A.-S., R. Biggs, S. Polasky, M. Troell, and A. de Zeeuw. 2012. Regime shifts and management. Ecological Economics 84:15-22. http://dx.doi.org/10.1016/j.ecolecon.2012.09.003

Crépin, A.-S., and T. Lindahl. 2009. Grazing games: sharing common property resources with complex dynamics. Environmental and Resource Economics 44:29-46. http://dx.doi. org/10.1007/s10640-008-9258-0

Folke, C., S. Carpenter, B. Walker, M. Scheffer, T. Elmqvist, L. Gunderson, and C. S. Holling. 2004. Regime shifts, resilience, and biodiversity in ecosystem management. Annual Review of Ecology, Evolution, and Systematics 35:557-581. http://dx.doi. org/10.1146/annurev.ecolsys.35.021103.105711

Gordon, L. J., G. D. Peterson, and E. M. Bennett. 2008. Agricultural modifications of hydrological flows create ecological surprises. Trends in Ecology and Evolution 23:211-219. http://dx. doi.org/10.1016/j.tree.2007.11.011

Gustafsson, M., A. Biel, and T. Gärling. 1999. Overharvesting of resources of unknown size. Acta Psychologica 103:47-64. http:// dx.doi.org/10.1016/S0001-6918(99)00024-4
Harrison, G. W., and J. A. List. 2004. Field experiments. Journal of Economic Literature 42:1009-1055. http://dx.doi. org/10.1257/0022051043004577

Hastings, A., and D. B. Wysham. 2010. Regime shifts in ecological systems can occur with no warning. Ecology Letters 13:464-472. http://dx.doi.org/10.1111/j.1461-0248.2010.01439.x

Henrich, J., S. J. Heine, and A. Norenzayan. 2010. The weirdest people in the world? Behavioral and Brain Sciences 33:61-83. http://dx.doi.org/10.1017/S0140525X0999152X

Hine, D. W., and R. Gifford. 1996. Individual restraint and group efficiency in commons dilemmas: the effects of two types of environmental uncertainty. Journal of Applied Social Psychology 26:993-1009. http://dx.doi.org/10.1111/j.1559-1816.1996.tb01121. $\underline{\mathrm{x}}$

Holling, C. S. 1987. Simplifying the complex: the paradigms of ecological function and structure. European Journal of Operational Research 30:139-146. http://dx.doi.org/10.1016/0377-2217 (87)90091-9

Janssen, M. A. 2010. Introducing ecological dynamics into common-pool resource experiments. Ecology and Society 15(2): 7. [online] URL: http://www.ecologyandsociety.org/vol15/iss $2 /$ $\underline{\operatorname{art} 7 /}$

Janssen, M. A., R. Holahan, A. Lee, and E. Ostrom. 2010. Lab experiments for the study of social-ecological systems. Science 328:613-617. http://dx.doi.org/10.1126/science.1183532

Janssen, M. A., A. Lee, and T. M. Waring. 2014. Experimental platforms for behavioral experiments on social-ecological systems. Ecology and Society 19(4): 20. http://dx.doi.org/10.5751/ ES-06895-190420

Kahneman, D., and A. Tversky. 1979. Prospect theory: an analysis of decision under risk. Econometrica 47:263-292. http://dx.doi. org/10.2307/1914185

Kimbrough, E. O., and A. Vostroknutov. 2013. The social and ecological determinants of common pool resource sustainability. Working paper. Indiana University, Bloomington, Indiana, USA. [online] URL: http://hdl.handle.net/10535/9106

Lade, S. J., and T. Gross. 2012. Early warning signals for critical transitions: a generalized modeling approach. PLoS Computational Biology 8(2):e1002360. http://dx.doi.org/10.1371/journal.pcbi.1002360

Levin, S. A. 1998. Ecosystems and the biosphere as complex adaptive systems. Ecosystems 1:431-436. http://dx.doi.org/10.1007/ $\underline{\mathrm{s} 100219900037}$

Levin, S., T. Xepapadeas, A.-S. Crépin, J. Norberg, A. de Zeeuw, C. Folke, T. Hughes, K. Arrow, S. Barrett, G. Daily, P. Ehrlich, N. Kautsky, K.-G. Mäler, S. Polasky, M. Troell, J. R. Vincent, and B. Walker. 2013. Social-ecological systems as complex adaptive systems: modeling and policy implications. Environment and Development Economics 18:111-132. http://dx.doi.org/10.1017/ $\underline{\mathrm{S} 1355770 \mathrm{X} 12000460}$

Likert, R. 1932. A technique for the measurement of attitudes. Archives of Psychology 140:1-55.

Lindahl, T., A.-S. Crépin, and C. Schill. 2012. Managing resources with potential regime shifts: using experiments to explore socialecological linkages in common resource system. Beijer Discussion 
Paper Series 232. Beijer Institute of Ecological Economics, Stockholm, Sweden.

Lindahl, T., A.-S. Crépin, and C. Schill. 2014. Potential disasters can turn the tragedy into success. Beijer Discussion Paper Series 244. Beijer Institute of Ecological Economics, Stockholm, Sweden.

Maddala, G. S. 1983. Limited-dependent and qualitative variables in econometrics. Cambridge University Press, Cambridge, Massachusetts, USA. http://dx.doi.org/10.1017/CBO9780511810176

Mäler, K.-G., A. Xepapadeas, and A. de Zeeuw. 2003. The economics of shallow lakes. Environmental and Resource Economics 26:603-624. http://dx.doi.org/10.1023/B: EARE.0000007351.99227.42

Messick, D. M., S. T. Allison, and C. D. Samuelson. 1988. Framing and communication effects on group members responses to environmental and social uncertainty. Pages 677-700 in $\mathrm{S}$. Maital, editor. Applied behavioral economics. New York University Press, New York, New York, USA.

Millennium Ecosystem Assessment. 2005. Ecosystems and human well-being: synthesis. Island Press, Washington, D.C., USA.

Moreno-Sánchez, R. P., and J. H. Maldonado. 2010. Evaluating the role of co-management in improving governance of marine protected areas: an experimental approach in the Colombian Caribbean. Ecological Economics 69:2557-2567. http://dx.doi. org/10.1016/j.ecolecon.2010.07.032

Norström, A. V., M. Nyström, J. Lokrantz, and C. Folke. 2009. Alternative states on coral reefs: beyond coral-macroalgal phase shifts. Marine Ecology Progress Series 376:295-306. http://dx.doi. org/10.3354/meps07815

Osés-Eraso, N., F. Udina, and M. Viladrich-Grau. 2008. Environmental versus human-induced scarcity in the commons: do they trigger the same response? Environmental and Resource Economics 40:529-550. http://dx.doi.org/10.1007/s10640-007-9168-6

Ostrom, E. 1990. Governing the commons: the evolution of institutions for collective action. Cambridge University Press, New York, New York, USA. http://dx.doi.org/10.1017/CBO9780511807763

Ostrom, E. 2006. The value-added of laboratory experiments for the study of institutions and common-pool resources. Journal of Economic Behavior \& Organization 61:149-163. http://dx.doi. org/10.1016/j.jebo.2005.02.008

Ostrom, E. 2009. A general framework for analyzing sustainability of social-ecological systems. Science 325:419-422. http://dx.doi.org/10.1126/science.1172133

Ostrom, E., R. Gardner, and J. Walker. 1994. Rules, games, and common-pool resources. University of Michigan Press, Ann Arbor, Michigan, USA.

Polasky, S., A. de Zeeuw, and F. Wagener. 2011. Optimal management with potential regime shifts. Journal of Environmental Economics and Management 62:229-240. http://dx. doi.org/10.1016/j.jeem.2010.09.004

Poteete, A. R., M. A. Janssen, and E. Ostrom. 2010. Working together: collective action, the commons, and multiple methods in practice. Princeton University Press, Princeton, New Jersey, USA. http://dx.doi.org/10.1515/9781400835157

Prediger, S., B. Vollan, and M. Frölich. 2011. The impact of culture and ecology on cooperation in a common-pool resource experiment. Ecological Economics 70:1599-1608. http://dx.doi. org/10.1016/j.ecolecon.2010.08.017

Pretty, J. 2003. Social capital and the collective management of resources. Science 302:1912-1914. http://dx.doi.org/10.1126/ science. 1090847

Rapoport, A., D. V. Budescu, R. Suleiman, and E. Weg. 1992. Social dilemmas with uniformly distributed resources. Pages 43-57 in W. B. G. Liebrand, D. M. Messick, and H. A. M. Wilke, editors. Social dilemmas: theoretical issues and research findings. Pergamon, Oxford, UK.

Rocha, J., J. Yletyinen, R. Biggs, T. Blenckner, and G. Peterson. 2015. Marine regime shifts: drivers and impacts on ecosystems services. Philosophical Transactions of the Royal Society B 370 (1659): 20130273. http://dx.doi.org/10.1098/rstb.2013.0273

Rockström, J., W. Steffen, K. Noone, Å. Persson, F. S. Chapin, III, E. Lambin, T. M. Lenton, M. Scheffer, C. Folke, H. J. Schellnhuber, B. Nykvist, C. A. De Wit, T. Hughes, S. Van der Leeuw, H. Rodhe, S. Sörlin, P. K. Snyder, R. Costanza, U. Svedin, M. Falkenmark, L. Karlberg, R. W. Corell, V. J. Fabry, J. Hansen, B. Walker, D. Liverman, K. Richardson, P. Crutzen, and J. Foley. 2009. Planetary boundaries: exploring the safe operating space for humanity. Ecology and Society 14(2): 32. [online] URL: http:// www.ecologyandsociety.org/vol14/iss $2 / \operatorname{art} 32 /$

Sally, D. 1995. Conversation and cooperation in social dilemmas: a meta-analysis of experiments from 1958 to 1992. Rationality and Society 7:58-92. http://dx.doi.org/10.1177/1043463195007001004

Scheffer, M., S. Carpenter, J. A. Foley, C. Folke, and B. Walker. 2001. Catastrophic shifts in ecosystems. Nature 413:591-596. http://dx.doi.org/10.1038/35098000

Scheffer, M., S. R. Carpenter, T. M. Lenton, J. Bascompte, W. Brock, V. Dakos, J. van de Koppel, I. A. van de Leemput, S. A. Levin, E. H. van Nes, M. Pascual, and J. Vandermeer. 2012. Anticipating critical transitions. Science 338:344-348. http://dx. doi.org/10.1126/science. 1225244

Schelling, T. C. 1960. The strategy of conflict. Harvard University Press, Cambridge, Massachusetts, USA.

Schill, C. 2012. Identifying factors influencing exploitation strategies and cooperation in commons dilemmas under threshold uncertainty: evidence from a laboratory experiment. Thesis. Stockholm University, Stockholm, Sweden.

Steffen, W., R. A. Sanderson, P. D. Tyson, J. Jäger, P. A. Matson, B. Moore, III, F. Oldfield, K. Richardson, H.-J. Schellnhuber, B. L. Turner, II, and R. J. Wasson. 2004. Global change and the earth system: a planet under pressure. Springer, Heidelberg, Germany.

Stern, N. 2007. The economics of climate change: the Stern review. Cambridge University Press, Cambridge, UK. http://dx.doi. org/10.1017/CBO9780511817434

Sturm, B., and J. Weimann. 2006. Experiment in environmental economics and some close relatives. Journal of Economic Surveys 20:419-458. http://dx.doi.org/10.1111/j.0950-0804.2006.00285.x 
Turner, B. L., II, R. E. Kasperson, P. A. Matson, J. J. McCarthy, R. W. Corell, L. Christensen, N. Eckley, J. X. Kasperson, A. Luers, M. L. Martello, C. Polsky, A. Pulsipher, and A. Schiller. 2003. A framework for vulnerability analysis in sustainability science. Proceedings of the National Academy of Sciences of the United States of America 100:8074-8079. http://dx.doi.org/10.1073/ pnas. 1231335100

Tversky, A., and D. Kahneman. 1973. Availability: a heuristic for judging frequency and probability. Cognitive Psychology 5:207-232. http://dx.doi.org/10.1016/0010-0285(73)90033-9

Tversky, A., and D. Kahneman. 1974. Judgment under uncertainty: heuristics and biases. Science 185:1124-1131. http:// dx.doi.org/10.1126/science.185.4157.1124

Tversky, A., and D. Kahneman. 1992. Advances in prospect theory: cumulative representation of uncertainty. Journal of Risk and Uncertainty 5:297-323. http://dx.doi.org/10.1007/BF00122574

Walker, J. M., and R. Gardner. 1992. Probabilistic destruction of common-pool resources: experimental evidence. Economic Journal 102:1149-1161. http://dx.doi.org/10.2307/2234382

Wilson, J. 2002. Scientific uncertainty, complex systems, and the design of common-pool institutions. Pages 327-359 in E. Ostrom, T. Dietz, N. Dolšak, P. C. Stern, S. Stonich, and E. U. Weber, editors. Drama of the commons. National Academy Press, Washington, D.C., USA. 
Appendix 1. Experiment instructions and form for subjects.

This appendix contains the English instructions (the Swedish instructions are available upon request) of the threshold treatment and the medium-risk treatment ( 0.5 probability of a threshold) as well as the form on which the subjects indicated their individual harvest decisions in each round. The high- and low-risk treatment instructions coincide with the medium-risk treatment except for the probabilities ( 0.9 and 0.1 instead of 0.5 ) and the information on how the experimenter decided upon which scenario will be played (by doing a random draw instead of flipping a coin).

Threshold treatment:

\section{INSTRUCTIONS}

Thank you for participating in this experiment! It is an experiment dealing with economic decision-making. If you follow the instructions carefully and take sound decisions, you can earn money. You will receive the compensation for your participation in this experiment (150 SEK) plus the additional earnings after the experiment.

Each of you sitting in this room is a fictive resource user. Together with the other experiment participants you form a group. You and your group members have common access to a resource stock. Each of you can harvest units of this resource. Each harvested unit is worth 5 SEK. Accordingly, in case your individual harvest amounts to 20 units at the end of the experiment, you will earn 100 SEK (in addition to the show-up fee of 150 SEK). The important thing you need to remember is that the more units you harvest the more money you earn.

The experiment lasts several rounds and in each round you take an individual decision of how many units of the resource you would like to harvest. The resource regenerates itself before each new round. The regeneration depends on how much of the resource stock is left from the previous round, which in turn depends on the total harvest of the previous round (sum of your and the other participants' harvest in the previous round). As long as there are units to harvest, the experiment continues for a number of rounds. The more rounds you succeed to sustain the resource the more you are able to harvest, and respectively earn, in total. The exact amount of rounds is unknown to you. If the group's total harvest is equal to or exceeding the number of 
available resource units in one round, the resource regeneration is zero and the experiment ends. The harvest you receive in that round $(\mathrm{X})$ is then based on your percentage of the group's total harvest in that round $(\mathrm{X}=($ your harvest/total harvest $)$ * resource stock size $)$.

The exact relation between the size of the resource stock and its regeneration is illustrated in Figure 1.

\section{Figure 1}

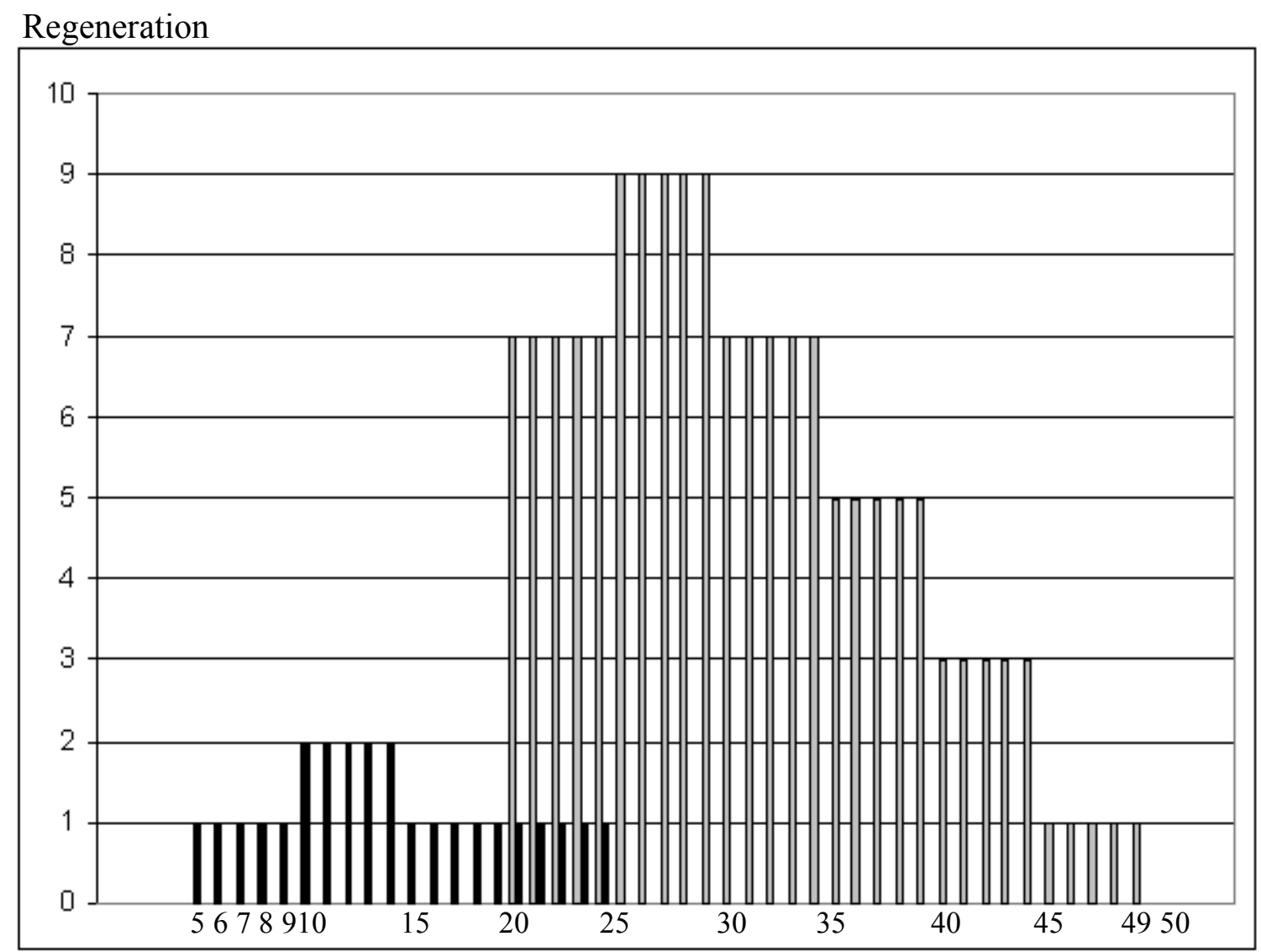

Units

As the figure illustrates, there is a "threshold" in the resource dynamics. If the size of the resource stock is equal to or lower than 19 units, the regeneration capacity decreases drastically. In order 
to get back to a higher regeneration capacity, the resource stock needs to reach an amount of 25 units or more.

There are 50 units of the resource in the beginning of the experiment. If you, for example, harvest together 17 units in the first round, the resource will regenerate itself by 7 units and, hence, the resource stock will consist of $(50-17+7)=40$ units in round 2 .

To ensure clarity, this regeneration process is also illustrated in Table 1.

Table 1

\begin{tabular}{|c|c|c|c|c|c|}
\hline $\begin{array}{l}\text { Resource } \\
\text { stock size }\end{array}$ & $\begin{array}{l}\text { Re- } \\
\text { generation }\end{array}$ & $\begin{array}{l}\text { Resource } \\
\text { stock size }\end{array}$ & $\begin{array}{l}\text { Re- } \\
\text { generation }\end{array}$ & $\begin{array}{l}\text { Resource } \\
\text { stock size }\end{array}$ & $\begin{array}{l}\text { Re- } \\
\text { generation }\end{array}$ \\
\hline 50 & 0 & 32 & 7 & 14 & 2 \\
\hline 49 & 1 & 31 & 7 & 13 & 2 \\
\hline 48 & 1 & 30 & 7 & 12 & 2 \\
\hline 47 & 1 & 29 & 9 & 11 & 2 \\
\hline 46 & 1 & 28 & 9 & 10 & 2 \\
\hline 45 & 1 & 27 & 9 & 9 & 1 \\
\hline 44 & 3 & 26 & 9 & 8 & 1 \\
\hline 43 & 3 & 25 & 9 & 7 & 1 \\
\hline 42 & 3 & 24 & 7 alt. 1 & 6 & 1 \\
\hline 41 & 3 & 23 & 7 alt. 1 & 5 & 1 \\
\hline 40 & 3 & 22 & 7 alt. 1 & 4 & 0 \\
\hline 39 & 5 & 21 & 7 alt. 1 & 3 & 0 \\
\hline 38 & 5 & 20 & 7 alt. 1 & 2 & 0 \\
\hline 37 & 5 & 19 & 1 & 1 & 0 \\
\hline 36 & 5 & 18 & 1 & 0 & 0 \\
\hline 35 & 5 & 17 & 1 & & \\
\hline 34 & 7 & 16 & 1 & & \\
\hline 33 & 7 & 15 & 1 & & \\
\hline
\end{tabular}


You take a decision about how many units (in whole numbers, between 0 and current resource stock size) you would like to harvest in each round. The individual decisions are communicated via protocol and are anonymous. However, this does not mean that you cannot communicate orally with each other. The leader of the experiment calculates the total harvest in each round, lowers the resource stock by this amount, calculates how many resource units regenerate and discloses the new size of the resource stock to you.

After the very last round, you are requested to fill in a short questionnaire. Following, the leader of the experiment calls each of you to her desk for the individual payment, which corresponds to your total harvest.

In case you have any questions during the experiment, raise your hand and the leader of the experiment will come to you.

Summary:

- You and the other participants in your group share one resource stock.

- In each round you will take an individual decision of how many units of the resource you would like to harvest.

- As long as the stock size of the resource is between 5 and 49, it regenerates itself every round.

- Since it is a common resource, the regeneration is dependent on the size of the resource stock and the total harvest. The exact relation is illustrated in Figure 1 and Table 1.

- Each unit harvested is worth 5 SEK.

- As long as the resource regenerates itself the experiment continues, while the exact number of rounds is unknown to you.

- Your harvest converts to SEK in the end of the experiment.

\section{Good luck!}


Medium-risk treatment:

\section{INSTRUCTIONS}

Thank you for participating in this experiment! It is an experiment dealing with economic decision-making. If you follow the instructions carefully and take sound decisions, you can earn money. You will receive the compensation for your participation in this experiment (SEK 150) plus the additional earnings after the experiment.

Each of you sitting in this room is a fictive resource user. Together with the other experiment participants you form a group. You and your group members have common access to a resource stock. Each of you can harvest units of this resource. Each harvested unit is worth SEK 5. Accordingly, in case your individual harvest amounts to 20 units at the end of the experiment, you will earn SEK 100 (in addition to the show-up fee of SEK 150). The important thing you need to re-member is that the more units you harvest the more money you earn.

The experiment lasts several rounds and in each round you take an individual decision of how many units of the resource you would like to harvest. The resource regenerates itself before each new round. The regeneration depends on how much of the resource stock is left from the previous round, which in turn depends on the total harvest of the previous round (sum of your and the other participants' harvest in the previous round). As long as there are units to harvest, the experiment continues for a number of rounds. The more rounds you succeed to sustain the resource the more you are able to harvest, and respectively earn, in total. The exact amount of rounds is un-known to you. If the group's total harvest is equal to or exceeding the number of available resource units in one round, the resource regeneration is zero and the experiment ends. The harvest you receive in that round $(\mathrm{H})$ is then based on your percentage of the group's total harvest in that round $(\mathrm{H}=($ your harvest/total harvest $)$ * resource stock size $)$.

There are two possible scenarios: scenario $\mathbf{A}$ and scenario $\mathbf{B}$. The exact relation between the size of the resource stock and its regeneration (resource dynamics) for both scenarios is 
illustrated in Figure 1 and 2 (following page). However, you do not know which of the two scenarios you will play. What you know is that there is a $90 \%$ chance that you play scenario A and a $10 \%$ chance that you play scenario B respectively.

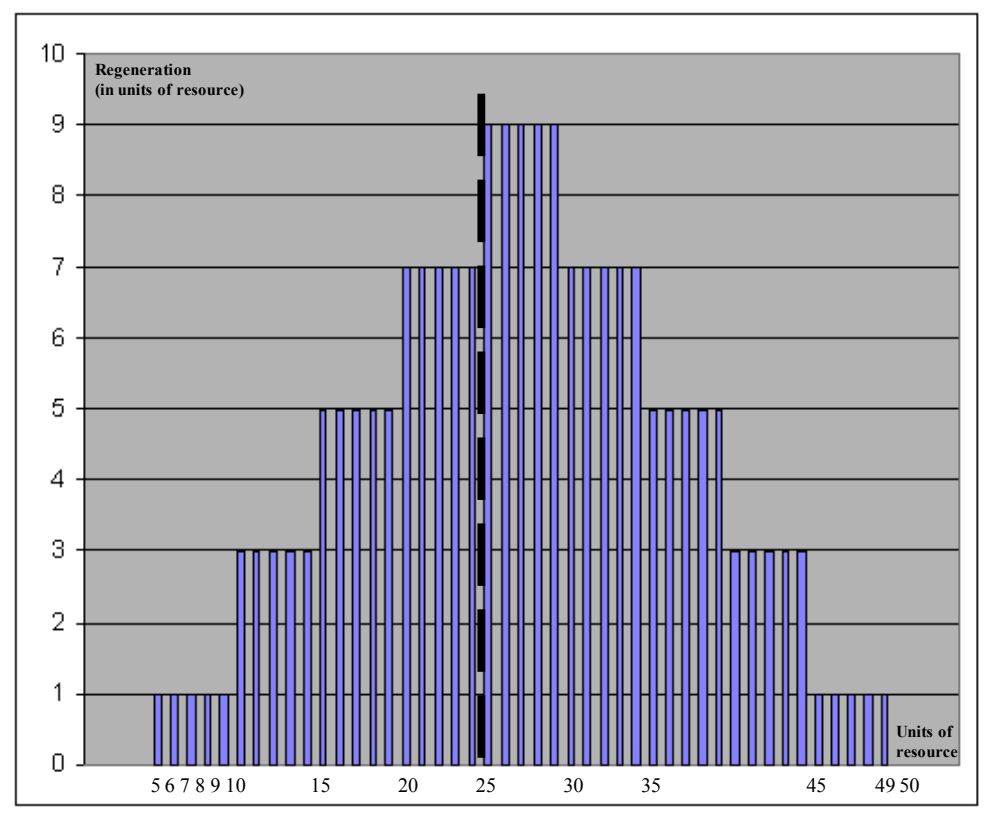

Figure 1: Resource dynamics scenario A (without threshold)

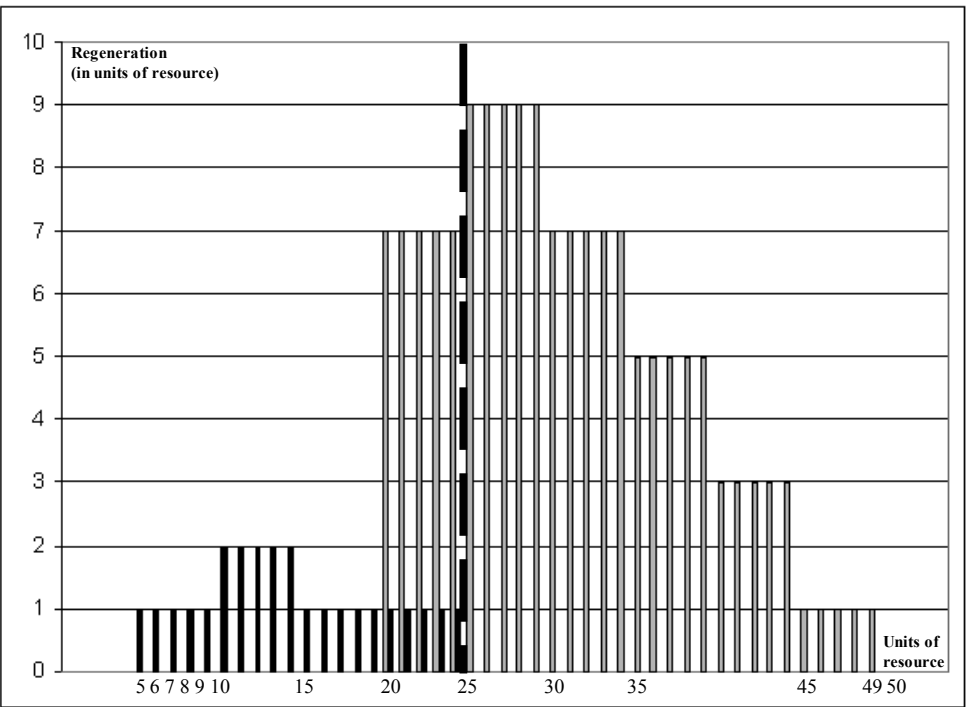

Figure 2: Resource dynamics scenario B (with threshold) 
As you can see from Figure 1 and 2, on the right hand side of the bold dashed line (resource stock size equal to and higher than 25 units) scenario $\mathrm{A}$ and $\mathrm{B}$ follow identical dynamics. The following example holds for both scenarios: There are 50 units of the resource in the beginning of the experiment. If your group, for example, harvests together 17 units in the first round, the resource will regenerate itself by 7 units and, hence, the resource stock will consist of $(50-17+7)=40$ units in round 2 .

On the left hand side of the bold dashed line (resource stock size equal to or lower than 24 units) scenario A and B differ from each other. As Figure 2 illustrates, there is a "threshold" in the resource dynamics of scenario B. If the size of the resource stock is equal to or lower than 19 units, the regeneration capacity decreases drastically. In order to get back to a higher regeneration capacity, the resource stock needs to reach an amount of 25 units or more.

To ensure clarity, the regeneration processes of both scenarios are also illustrated in Table 1.

Table 1: Resource dynamics of scenario $A$ and scenario $B$

\begin{tabular}{|c|c|c|c|c|c|c|c|c|c|c|c|}
\hline \multirow[t]{2}{*}{$\begin{array}{l}\text { Resource } \\
\text { stock size }\end{array}$} & \multicolumn{2}{|c|}{$\begin{array}{l}\text { Regeneration } \\
\text { (in units of } \\
\text { resource) }\end{array}$} & \multirow[t]{2}{*}{$\begin{array}{l}\text { Resource } \\
\text { stock size }\end{array}$} & \multicolumn{2}{|c|}{$\begin{array}{l}\text { Regeneration } \\
\text { (in units of } \\
\text { resource) }\end{array}$} & \multirow[t]{2}{*}{$\begin{array}{l}\text { Resource } \\
\text { stock size }\end{array}$} & \multicolumn{2}{|c|}{$\begin{array}{l}\text { Regeneration } \\
\text { (in units of } \\
\text { resource) }\end{array}$} & \multirow[t]{2}{*}{$\begin{array}{l}\text { Resource } \\
\text { stock size }\end{array}$} & \multicolumn{2}{|c|}{$\begin{array}{l}\text { Regeneration } \\
\text { (in units of } \\
\text { resource) }\end{array}$} \\
\hline & $\mathbf{A}$ & B & & $\mathbf{A}$ & B & & $\mathbf{A}$ & B & & $\mathbf{A}$ & B \\
\hline 50 & 0 & 0 & 37 & 5 & 5 & 24 & 7 & 7 alt. 1 & 11 & 3 & 2 \\
\hline 49 & 1 & 1 & 36 & 5 & 5 & 23 & 7 & 7 alt. 1 & 10 & 3 & 2 \\
\hline 48 & 1 & 1 & 35 & 5 & 5 & 22 & 7 & 7 alt. 1 & 9 & 1 & 1 \\
\hline 47 & 1 & 1 & 34 & 7 & 7 & 21 & 7 & 7 alt. 1 & 8 & 1 & 1 \\
\hline 46 & 1 & 1 & 33 & 7 & 7 & 20 & 7 & 7 alt. 1 & 7 & 1 & 1 \\
\hline 45 & 1 & 1 & 32 & 7 & 7 & 19 & 5 & 1 & 6 & 1 & 1 \\
\hline 44 & 3 & 3 & 31 & 7 & 7 & 18 & 5 & 1 & 5 & 1 & 1 \\
\hline 43 & 3 & 3 & 30 & 7 & 7 & 17 & 5 & 1 & 4 & 0 & 0 \\
\hline 42 & 3 & 3 & 29 & 9 & 9 & 16 & 5 & 1 & 3 & 0 & 0 \\
\hline 41 & 3 & 3 & 28 & 9 & 9 & 15 & 5 & 1 & 2 & 0 & 0 \\
\hline 40 & 3 & 3 & 27 & 9 & 9 & 14 & 3 & 2 & 1 & 0 & 0 \\
\hline 39 & 5 & 5 & 26 & 9 & 9 & 13 & 3 & 2 & 0 & 0 & 0 \\
\hline 38 & 5 & 5 & 25 & 9 & 9 & 12 & 3 & 2 & & & \\
\hline
\end{tabular}


As you can also see here, the regeneration rate of both scenarios is identical for a resource stock size between 50 and 25 units and between 9 and 0 units. The grey cells indicate the range of the resource stock size where the regeneration rate of scenario A and B differ from each other. The following examples point out the differences in the resource dynamics of scenario A and B.

Example scenario A: There are 25 units of the resource at the beginning of round $\mathrm{X}$. If your group, for example, harvests in total 10 units in that round, the resource will regenerate itself by 5 units and, hence, the resource stock will consist of $(25-10+5)=20$ units in the following round.

Example scenario B: There are 25 units of the resource at the beginning of round $\mathrm{X}$. If your group, for example, harvests in total 10 units in that round, the resource will regenerate itself by 1 unit and, hence, the resource stock will consist of $(25-10+1)=16$ units in the following round. You take a decision about how many units (in whole numbers, between 0 and current resource stock size) you would like to harvest in each round. The individual decisions are communicated via protocol and are anonymous. However, this does not mean that you cannot communicate orally with each other. The leader of the experiment calculates the total harvest in each round, lowers the resource stock by this amount, calculates how many resource units regenerate and discloses the new size of the resource stock to you.

After the very last round, you are requested to fill in a short questionnaire. Following, the leader of the experiment calls each of you to her desk for the individual payment, which corresponds to your total harvest plus the show-up fee.

In case you have any questions during the experiment, raise your hand and the leader of the experiment will come to you.

\section{Summary:}

- You and the other participants in your group share one resource stock. 
- In each round you will take an individual decision of how many units of the resource you would like to harvest.

- As long as the stock size of the resource is between 5 and 49, it regenerates itself every round.

- There are two possible scenarios: scenario A (without a threshold) and scenario B (with a threshold). However, which scenario is played is unknown to you.

- Which of the two scenarios you will play was decided by coin flipping.

- Since it is a common resource, the regeneration is dependent on the size of the resource stock and the total harvest. The exact relation is illustrated in Figure 1 and 2 as well as in Table 1.

- $\quad$ Each unit harvested is worth SEK 5.

- As long as the resource regenerates itself the experiment continues, while the exact number of rounds is unknown to you.

- Your harvest converts to SEK in the end of the experiment.

\section{Good luck!}


Form for subjects:

Participant no.

\begin{tabular}{|c|c|c|c|c|c|}
\hline Round & Harvest & Round & Harvest & Round & Harvest \\
\hline & & & & & \\
\hline & & & & & \\
\hline & & & & & \\
\hline & & & & & \\
\hline & & & & & \\
\hline & & & & & \\
\hline & & & & & \\
\hline & & & & & \\
\hline & & & & & \\
\hline & & & & & \\
\hline & & & & & \\
\hline & & & & & \\
\hline & & & & & \\
\hline
\end{tabular}


Appendix 2. Postexperimental questionnaire.

This appendix contains the latest version of the postexperimental questionnaire.

\section{Post-experiment questionnaire}

Your participant no.

What is your age?

What is your gender? Female Male

What is your nationality?

If you are a student:

How many semesters did you study so far in total?

What do you study (program/course)?

If you are not a student:

What is your educational background?

What is your current occupation?

How many in your group did you know from before? _ From where?

Have you been part of a similar experiment before? Yes _ No

How did you get informed about the experiment?

Through an advertisement on campus

Through an advertisement at Lappis

Through one of the experiment leaders Through a friend

\section{Questions about the experiment}

Right before the experiment ended, I expected the experiment to last for at least one more round.

$\begin{array}{lllllll}\text { Strongly disagree } & 1 & 2 & 3 & 4 & 5 & \text { Strongly agree }\end{array}$

Right before the experiment ended, for how many more rounds did you expect the experiment to continue?

No more round _ $1-3$ rounds more _ $4-6$ rounds more $\_$7-9 rounds more $\_\geq 10$ rounds more

Assume you would have known in which round the experiment ends, would you have harvested the remaining resource units in the last round? Yes No

\section{To what extent do you disagree/agree with the following statements?}

I got a good understanding about how the resource changed over time.

$\begin{array}{lllllll}\text { Strongly disagree } & 1 & 2 & 3 & 4 & 5 & \text { Strongly agree }\end{array}$

The instructions and explanations by the experimenters alone provided me with enough information to understand the relation between the resource stock size and our harvest decisions.

$\begin{array}{lllllll}\text { Strongly disagree } & 1 & 2 & 3 & 4 & 5 & \text { Strongly agree }\end{array}$ 
Without group discussions, I would not have developed the same understanding of that relation.

$\begin{array}{lllllll}\text { Strongly disagree } & 1 & 2 & 3 & 4 & 5 & \text { Strongly agree }\end{array}$

My understanding of that relation improved during the course of the experiment.

$\begin{array}{lllllll}\text { Strongly disagree } & 1 & 2 & 3 & 4 & 5 & \text { Strongly agree }\end{array}$

Our group managed to cooperate.

$\begin{array}{lllllll}\text { Strongly disagree } & 1 & 2 & 3 & 4 & 5 & \text { Strongly agree }\end{array}$

The communication in our group was effective. We reached agreements.

$\begin{array}{lllllll}\text { Strongly disagree } & 1 & 2 & 3 & 4 & 5 & \text { Strongly agree }\end{array}$

There was a leader of discussion in our group.

$\begin{array}{llllllll}\text { Strongly disagree } & 1 & 2 & 3 & 4 & 5 & \text { Strongly agree }\end{array}$

There was a high level of trust in our group.

$\begin{array}{lllllll}\text { Strongly disagree } & 1 & 2 & 3 & 4 & 5 & \text { Strongly agree }\end{array}$

Fairness played a role in my decision-making.

$\begin{array}{llllllll}\text { Strongly disagree } & 1 & 2 & 3 & 4 & 5 & \text { Strongly agree }\end{array}$

We shared the harvest equally.

$\begin{array}{lllllll}\text { Strongly disagree } & 1 & 2 & 3 & 4 & 5 & \text { Strongly agree }\end{array}$

While taking my decisions, I took previous decisions of my group members into account.

$\begin{array}{lllllll}\text { Strongly disagree } & 1 & 2 & 3 & 4 & 5 & \text { Strongly agree }\end{array}$

While taking my decisions, I took into account whether or not they affect the earnings of my group members.

$\begin{array}{lllllll}\text { Strongly disagree } & 1 & 2 & 3 & 4 & 5 & \text { Strongly agree }\end{array}$

It was important to me to avoid crossing the threshold.

$\begin{array}{lllllll}\text { Strongly disagree } & 1 & 2 & 3 & 4 & 5 & \text { Strongly agree }\end{array}$

If you did NOT communicate/take part in the group discussion - why? (You can tick several options.)

Out of shyness __ Lack of knowledge ___ Language barriers

There was no need for communication _ _ Other reason(s)

The money I earn through participating in this experiment is a substantial contribution to my monthly budget. (PLEASE ANSWER THIS QUESTION AFTER YOU HAVE RECEIVED YOUR EARNINGS!)

$\begin{array}{lllllll}\text { Strongly disagree } & 1 & 2 & 3 & 4 & 5 & \text { Strongly agree }\end{array}$

What is your monthly income (i.e. how much money do you have available to spend each month including rent)?

$$
<\operatorname{SEK} 7,000 \text { _ SEK } 7,000-9,000 \ldots \quad>\text { SEK } 9,000
$$


There are 27 units of the resource in the current round. If your group harvests together 5 resource units, how many resource units will there be in the following round?

Answer for scenario $A$

Answer for scenario $B$

There are 16 units of the resource in the current round. If your group harvests together 6 resource units, how many resource units will there be in the following round?
Answer for scenario $A$
Answer for scenario $B$

Assume you (yourself) were the only resource user, i.e. no one but you harvests the resource.

What would be your harvest claim in the first round (in resource units)?

Answer for scenario $A$

Answer for scenario $B$

What would be your harvest claim in the second round (in resource units)?

Answer for scenario $A$

Answer for scenario $B$

\section{General questions}

Generally speaking, I only trust people that I have known for a while.

$\begin{array}{lllllll}\text { Strongly disagree } & 1 & 2 & 3 & 4 & 5 & \text { Strongly agree }\end{array}$

Generally speaking, there are only a few people I can trust completely.

$\begin{array}{lllllll}\text { Strongly disagree } & 1 & 2 & 3 & 4 & 5 & \text { Strongly agree }\end{array}$

Generally speaking, I think of myself as someone that can be trusted.

$\begin{array}{lllllll}\text { Strongly disagree } & 1 & 2 & 3 & 4 & 5 & \text { Strongly agree }\end{array}$

Generally speaking, I express my opinion and thoughts openly and feel comfortable in discussions.

$\begin{array}{lllllll}\text { Strongly disagree } & 1 & 2 & 3 & 4 & 5 & \text { Strongly agree }\end{array}$

Generally speaking, I enjoy working in teams.

$\begin{array}{lllllll}\text { Strongly disagree } & 1 & 2 & 3 & 4 & 5 & \text { Strongly agree }\end{array}$

Imagine you could give some of the money you earn through participating in this experiment to charity. Would you do that? Yes No

If yes, how much of your earnings (in \%) would you give? Please indicate with a cross on the scale below. You can also cross between markings.

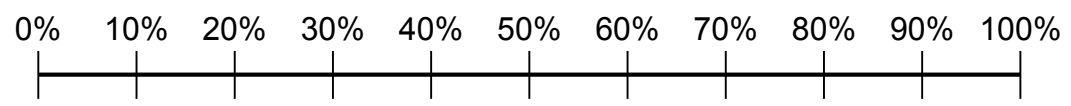

And which charity would you chose for example?

Other comments? 
Appendix 3. Supplementary material to statistical analysis and detailed group information.

This appendix contains specifications on the statistical tests and software we used as well as a description of variables used for the statistical analysis (see Table A3.1) and an overview of detailed group information (Table A3.2).

Preceding each statistical test, we applied the Shapiro-Wilk test (Shapiro and Wilk 1965) to test whether or not the data was normally distributed. If the test produced positive results at a $5 \%$ significance level, we rejected the assumption of normality and we reported results of non-parametric tests. To compare proportions across the treatments, we used a Pearson's chisquare test (D’Agostino et al. 1988) or a Fisher's exact test respectively, depending on the case frequencies (Kanji 1993).

All reported p-values are two-sided. All variables used display (mean) group values. We consider for all four treatments the first 14 rounds of the game for our analysis. We used the statistical software STATA 12.1 from 2012.

As for the logistic regressions, we tested for specification errors, goodness-of-fit, multicollinearity as well as for influential observations (do-files are available upon request). The reported models hold these diagnostics.

Table A3.1. Description of variables used for analysis. All variables display (mean) group values.

\begin{tabular}{|c|c|c|}
\hline Variable & $\begin{array}{l}\text { Value } \\
\text { range }\end{array}$ & Description \\
\hline $\begin{array}{l}\text { Crossing potential threshold } \\
\text { (severe overexploitation) }\end{array}$ & $0 \vee 1$ & Group crosses the potential threshold within 14 rounds. \\
\hline Modest overexploitation & $0 \vee 1$ & $\begin{array}{l}\text { Group exploits the resource above what is optimal at some point } \\
\text { during the game but does not cross the potential threshold. }\end{array}$ \\
\hline Depletion & $0 \vee 1$ & $\begin{array}{l}\text { Group depletes the resource stock. When depletion happens in } \\
\text { agreement, we refer to cooperative depletion. }\end{array}$ \\
\hline Cooperative group & $0 \vee 1$ & $\begin{array}{l}\text { Group is able to reach agreement with respect to its exploitation } \\
\text { strategy for the entire experiment and the agreements followed } \\
\text { by all group members, i.e., with no cheating. }\end{array}$ \\
\hline Group agreement round one & $0 \vee 1$ & $\begin{array}{l}\text { Group uses the communication possibility to reach an agreement } \\
\text { on harvest strategy in the first round. This does not imply that } \\
\text { subjects actually follow this agreement. }\end{array}$ \\
\hline Efficiency & {$[0,1]$} & Share of actual joint earnings over the maximum possible. \\
\hline $\begin{array}{l}\text { Gini coefficient } \\
\text { (individual earnings) }\end{array}$ & {$[0,1]$} & Represents the distribution of individual earnings within a group. \\
\hline $\begin{array}{l}\text { Understanding of resource } \\
\text { dynamics }^{\dagger}\end{array}$ & {$[1,5]$} & $\begin{array}{l}\text { Perceived understanding about how the resource changes over } \\
\text { time. }\end{array}$ \\
\hline Gender composition $^{\dagger}$ & {$[0,1]$} & This variable is dichotomous on individual level ( $1=$ female $)$. \\
\hline Group of 4 subjects & $0 \vee 1$ & Groups consist of three or four subjects ( $1=$ four subjects $)$. \\
\hline Weird index ${ }^{\dagger}$ & {$[0,1]$} & $\begin{array}{l}\text { This variable is dichotomous on individual level. Subject from a } \\
\text { western, educated, industrialized, rich, democratic (weird) } \\
\text { country =1, see Henrich et al. (2010). European, North } \\
\text { American, and Australian subjects are here classified as such. }\end{array}$ \\
\hline
\end{tabular}


Know others from before ${ }^{+}$

Age $^{+}$
$[0,1]$ This variable is dichotomous on group level $(1=$ at least one subject indicated knowing someone else from before).

$>18$ Number of years spent as part of the biosphere.

${ }^{+}$Variables obtained from postexperimental questionnaire (see Appendix 2).

See Table A3.2 on next page. 
Table A3.2. Detailed group information.

\begin{tabular}{|c|c|c|c|c|c|c|c|c|c|c|c|}
\hline $\begin{array}{l}\text { Group } \\
\text { name }\end{array}$ & $\begin{array}{l}\text { Group } \\
\text { no. }\end{array}$ & $\begin{array}{l}\text { \# sub- } \\
\text { jects }\end{array}$ & $\begin{array}{l}\text { Coop. } \\
\text { group }\end{array}$ & $\begin{array}{l}\text { Gini } \\
\text { coef. } \\
=0\end{array}$ & $\begin{array}{l}\text { Crossing } \\
\text { potential } \\
\text { threshold }\end{array}$ & Depletion & $\begin{array}{l}\text { Modest } \\
\text { over- } \\
\text { expl. }\end{array}$ & $\begin{array}{l}\text { Group } \\
\text { agree- } \\
\text { ment } \\
\text { round } \\
\text { one }\end{array}$ & Reasons for crossing potential threshold & Reasons for depletion & $\begin{array}{l}\text { EOG } \\
\text { effect? }\end{array}$ \\
\hline
\end{tabular}

\section{Threshold treatment}

\begin{tabular}{|c|c|c|c|c|c|c|c|c|c|}
\hline $\mathrm{A} 03$ & 1 & 3 & Yes & No & No & No & No & Yes & -- \\
\hline B01" & 2 & 3 & Yes & Yes & No & No & No & Yes & -- \\
\hline B02 & 3 & 4 & Yes & No & No & No & No & Yes & -- \\
\hline C01 & 4 & 3 & Yes & Yes & No & No & Yes & Yes & -- \\
\hline $\mathrm{CT} 1^{1}$ & 5 & 4 & No & No & No & No & No & Yes & -- \\
\hline $\mathrm{CT} 2^{\prime}$ & 6 & 4 & Yes & Yes & No & No & Yes & Yes & -- \\
\hline $\mathrm{CT} 3^{1,9}$ & 7 & 4 & Yes & Yes & No & No & No & Yes & -- \\
\hline CT4 & 8 & 4 & Yes & Yes & No & No & No & Yes & -- \\
\hline CT5 & 9 & 4 & No & No & No & No & No & Yes & -- \\
\hline E02 & 10 & 4 & No & No & $\begin{array}{l}\text { Yes, in } \\
\text { round } 12\end{array}$ & $\begin{array}{l}\text { Yes, in } \\
\text { round } 13\end{array}$ & No & Yes & $\mathrm{n} / \mathrm{a}$ \\
\hline T01 & 11 & 4 & No & No & $\begin{array}{l}\text { Yes, in } \\
\text { round } 1^{\ddagger}\end{array}$ & No & No & No & $\begin{array}{l}\text { Group agreement in round one only between } 3 / 4 \\
\text { subjects, the one that did not agree took out } 20 \\
\text { resource stock units. }\end{array}$ \\
\hline
\end{tabular}

$\begin{array}{llllllllll}\text { T02 } & 12 & 4 & \text { Yes } & \text { No } & \text { No } & \text { No } & \text { No } & \text { Yes } & -- \\ \text { T03 } & 13 & 3 & \text { Yes } & \text { No } & \text { No } & \text { No } & \text { No } & \text { Yes } & -- \\ \text { T04 } & 14 & 3 & \text { Yes } & \text { No } & \text { No } & \text { No } & \text { No } & \text { Yes } & -- \\ \text { T05 } & 15 & 4 & \text { Yes } & \text { Yes } & \text { No } & \text { No } & \text { No } & \text { Yes } & -- \\ \text { T06" } & 16 & 3 & \text { Yes } & \text { Yes } & \text { No } & \text { No } & \text { No } & \text { Yes } & -- \\ \text { T07 } & 17 & 4 & \text { Yes } & \text { Yes } & \text { No } & \text { No } & \text { No } & \text { Yes } & -- \\ \text { T08 } & 18 & 3 & \text { Yes } & \text { Yes } & \text { No } & \text { No } & \text { Yes } & \text { Yes } & -- \\ \text { T09 } & 19 & 4 & \text { Yes } & \text { No } & \text { No } & \text { No } & \text { No } & \text { Yes } & - \\ \text { T10 } & 20 & 4 & \text { Yes } & \text { No } & \text { No } & \text { No } & \text { No } & \text { Yes } & --\end{array}$

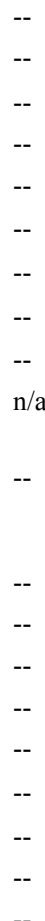

$\mathrm{n} / \mathrm{a}$

$-$

High-risk treatment

\begin{tabular}{|c|c|c|c|c|c|c|c|c|c|}
\hline $\mathrm{UHT} 1^{+}$ & 21 & 3 & No & No & $\begin{array}{l}\text { Yes, in } \\
\text { round } 10\end{array}$ & No & -- & No & $\begin{array}{l}\text { Combination of poor communication (unclear group } \\
\text { agreement) and one subject that took much more } \\
\text { than the others in round } 10 .\end{array}$ \\
\hline $\mathrm{UHT} 2^{+}$ & 22 & 3 & No & No & No & No & No & No & -- \\
\hline
\end{tabular}




\begin{tabular}{|c|c|c|c|c|c|c|c|c|c|c|c|}
\hline $\mathrm{UHT} 3^{+}$ & 23 & 4 & No & No & No & No & Yes & Yes & -- & -- & -- \\
\hline UHT04 & 24 & 3 & No & No & $\begin{array}{l}\text { Yes, in } \\
\text { round } 11\end{array}$ & $\begin{array}{l}\text { Yes, in } \\
\text { round } 12\end{array}$ & -- & Yes & One subject harvested more than agreed upon. & $\begin{array}{l}\text { Trust eroded, decision of the other two subjects to } \\
\text { deplete stock in round after they crossed the } \\
\text { threshold by taking each the available stock size. }\end{array}$ & No \\
\hline $\mathrm{UHT}^{+} 5^{\dagger, \uparrow}$ & 25 & 4 & Yes & Yes & No & No & No & Yes & -- & -- & -- \\
\hline $\mathrm{UHT}^{\dagger}{ }^{\dagger}$ & 26 & 4 & No & No & No & No & No & Yes & -- & -- & -- \\
\hline $\mathrm{UHT} 7^{+}$ & 27 & 4 & Yes & Yes & No & No & Yes & Yes & -- & -- & -- \\
\hline $\mathrm{UHT}^{+} 8^{+}$ & 28 & 3 & No & No & $\begin{array}{l}\text { Yes, in } \\
\text { round } 10\end{array}$ & No & -- & Yes & $\begin{array}{l}\text { Crossed the threshold on purpose, group wanted to } \\
\text { know which scenario they play. }\end{array}$ & -- & -- \\
\hline $\mathrm{UHT}^{+} 9^{+}$ & 29 & 4 & No & No & No & No & Yes & Yes & -- & -- & -- \\
\hline $\mathrm{UHT} 0^{+}$ & 30 & 4 & No & No & $\begin{array}{l}\text { Yes, in } \\
\text { round } 2\end{array}$ & $\begin{array}{l}\text { Yes, in } \\
\text { round } 3\end{array}$ & -- & No & $\begin{array}{l}\text { Combination of cheating and misunderstanding of } \\
\text { the cheater regarding the hysteresis effect. }\end{array}$ & $\begin{array}{l}\text { Trust eroded, all but one subject harvested more than } \\
\text { agreed upon (harvest of } 1 \text { resource stock unit) which } \\
\text { lead to depletion of the resource. }\end{array}$ & No \\
\hline $\mathrm{UHT}_{1} 1^{+}$ & 31 & 3 & Yes & No & No & $\begin{array}{l}\text { Yes, in } \\
\text { round } 12^{\S}\end{array}$ & No & Yes & -- & Due to believe that game would end soon. & Yes \\
\hline UHT12" & 32 & 4 & Yes & Yes & No & No & No & Yes & -- & -- & -- \\
\hline $\mathrm{UHT}_{1} 3^{+}$ & 33 & 4 & Yes & Yes & No & No & Yes & Yes & -- & -- & -- \\
\hline $\mathrm{UHT}_{1} 4^{+}$ & 34 & 3 & Yes & No & No & No & No & Yes & -- & -- & -- \\
\hline UHT15 & 35 & 4 & Yes & Yes & No & No & No & Yes & -- & -- & -- \\
\hline $\mathrm{UHT} 16^{+}$ & 36 & 4 & No & No & No & No & No & Yes & -- & -- & -- \\
\hline $\mathrm{UHT}_{1} 7^{+}$ & 37 & 3 & No & No & $\begin{array}{l}\text { Yes, in } \\
\text { round } 6^{\ddagger}\end{array}$ & No & -- & Yes & $\begin{array}{l}\text { Crossed the threshold on purpose, group wanted to } \\
\text { know which scenario they play. }\end{array}$ & -- & -- \\
\hline UHT18 & 38 & 4 & Yes & No & No & No & No & Yes & -- & -- & -- \\
\hline $\mathrm{UHT} 9^{+}$ & 39 & 4 & Yes & No & No & No & Yes & Yes & -- & -- & -- \\
\hline $\mathrm{UHT} 0^{+}$ & 40 & 4 & No & No & No & No & Yes & Yes & -- & -- & -- \\
\hline UHT $21^{+}$ & 41 & 4 & No & No & $\begin{array}{l}\text { Yes, in } \\
\text { round } 8\end{array}$ & $\begin{array}{l}\text { Yes, in } \\
\text { round } 12\end{array}$ & -- & Yes & $\begin{array}{l}\text { Combination of cheating and misunderstanding of } \\
\text { the cheater regarding the hysteresis effect. }\end{array}$ & $\begin{array}{l}\text { Trust eroded and although they initially decided to } \\
\text { rebuild the resource stock, in round } 12 \text {, one subject } \\
\text { took it all. }\end{array}$ & No \\
\hline \multicolumn{12}{|c|}{ Medium-risk treatment } \\
\hline $\mathrm{U} 01^{\natural}$ & 42 & 3 & Yes & Yes & No & No & No & Yes & -- & -- & -- \\
\hline $\mathrm{U} 02^{+}$ & 43 & 4 & Yes & No & No & No & No & Yes & -- & -- & -- \\
\hline $\mathrm{U} 03^{+}$, q & 44 & 4 & Yes & Yes & No & No & No & Yes & -- & -- & -- \\
\hline U04 & 45 & 3 & Yes & No & No & No & No & Yes & -- & -- & -- \\
\hline $\mathrm{U} 05^{\dagger}$ & 46 & 4 & Yes & No & No & No & No & Yes & -- & -- & -- \\
\hline $\mathrm{U} 06^{+}, 9$ & 47 & 3 & Yes & Yes & No & No & No & Yes & -- & -- & -- \\
\hline U07 & 48 & 4 & Yes & No & No & No & No & Yes & -- & -- & -- \\
\hline
\end{tabular}




\begin{tabular}{|c|c|c|c|c|c|c|c|c|c|c|c|}
\hline $\mathrm{U} 08^{+}$ & 49 & 4 & Yes & No & No & No & No & Yes & -- & -- & -- \\
\hline U09 & 50 & 3 & No & No & $\begin{array}{l}\text { Yes, in } \\
\text { round } 2\end{array}$ & $\begin{array}{l}\text { Yes, in } \\
\text { round } 5\end{array}$ & No & No & Poor communication (weak group agreements). & $\begin{array}{l}\text { No agreements for rebuilding the stock, stock } \\
\text { decreases to } 5 \text { units and then they deplete it. }\end{array}$ & No \\
\hline $\mathrm{U} 10^{+}$, & 51 & 4 & Yes & Yes & No & No & No & Yes & -- & -- & -- \\
\hline $\mathrm{U} 11^{+, \pi}$ & 52 & 4 & Yes & Yes & No & No & No & Yes & -- & -- & -- \\
\hline $\mathrm{U} 12^{+}$ & 53 & 4 & Yes & No & No & No & No & Yes & -- & -- & -- \\
\hline U13 & 54 & 4 & Yes & No & No & No & No & Yes & -- & -- & -- \\
\hline U14 & 55 & 4 & Yes & No & No & No & No & Yes & -- & -- & -- \\
\hline $\mathrm{U} 15^{\dagger}$, & 56 & 4 & Yes & Yes & $\begin{array}{l}\text { Yes, in } \\
\text { round } 10\end{array}$ & $\begin{array}{l}\text { Yes, in } \\
\text { round } 11^{\S}\end{array}$ & No & Yes & Miscalculation of group. & $\begin{array}{l}\text { When they realized the calculation mistake in the } \\
\text { round after they crossed the threshold (and that they } \\
\text { played scenario B), they decide to end the game by } \\
\text { depleting the remaining resource stock. }\end{array}$ & No \\
\hline $\mathrm{U} 16^{+}$ & 57 & 4 & No & No & $\begin{array}{l}\text { Yes, in } \\
\text { round } 14\end{array}$ & No & No & No & Two subjects harvested more than agreed upon. & -- & -- \\
\hline $\mathrm{U} 17^{+}$ & 58 & 4 & Yes & No & No & No & No & Yes & -- & -- & -- \\
\hline $\mathrm{U} 18^{+}$ & 59 & 4 & No & No & No & No & Yes & No & -- & -- & -- \\
\hline $\mathrm{U} 19^{+}$ & 60 & 4 & No & No & $\begin{array}{l}\text { Yes, in } \\
\text { round } 1^{\ddagger}\end{array}$ & No & No & No & $\begin{array}{l}\text { No communication in round one (in which they } \\
\text { crossed the threshold). }\end{array}$ & -- & -- \\
\hline $\mathrm{U} 20$ & 61 & 4 & Yes & Yes & No & No & Yes & Yes & -- & -- & -- \\
\hline $\mathrm{U} 21$ & 62 & 4 & Yes & No & No & No & No & Yes & -- & -- & -- \\
\hline $\mathrm{U} 22$ & 63 & 4 & No & No & $\begin{array}{l}\text { Yes, in } \\
\text { round } 7\end{array}$ & $\begin{array}{l}\text { Yes, in } \\
\text { round } 8^{\S}\end{array}$ & No & Yes & Miscalculation of group. & $\begin{array}{l}\text { When they realized the calculation mistake in the } \\
\text { round after they crossed the potential threshold, they } \\
\text { decide to end the game by depleting the remaining } \\
\text { resource stock. The group did not realize that they } \\
\text { actually played scenario A. }\end{array}$ & No \\
\hline $\mathrm{U} 23$ & 64 & 3 & No & No & $\begin{array}{l}\text { Yes, in } \\
\text { round } 14\end{array}$ & No & No & No & $\begin{array}{l}\text { Crossed the threshold on purpose, group wanted to } \\
\text { know which scenario they play. }\end{array}$ & -- & -- \\
\hline \multicolumn{12}{|c|}{ Low-risk treatment } \\
\hline ULT01 & 65 & 3 & No & No & No & No & Yes & Yes & -- & -- & -- \\
\hline ULT02 & 66 & 4 & Yes & Yes & No & $\begin{array}{l}\text { Yes, in } \\
\text { round } 7^{\S}\end{array}$ & Yes & Yes & -- & Due to believe that game would end soon. & Yes \\
\hline ULT03 & 67 & 3 & Yes & No & No & No & No & Yes & -- & -- & -- \\
\hline ULT04 & 68 & 3 & No & No & $\begin{array}{l}\text { Yes, in } \\
\text { round } 4\end{array}$ & No & No & No & No communication at all. & -- & -- \\
\hline $\mathrm{ULT} 5^{+}$ & 69 & 3 & Yes & No & $\begin{array}{l}\text { Yes, in } \\
\text { round } 10\end{array}$ & $\begin{array}{l}\text { Yes, in } \\
\text { round } 12^{\S}\end{array}$ & No & Yes & $\begin{array}{l}\text { Crossed the threshold on purpose, group wanted to } \\
\text { know which scenario they play and slowly decrease } \\
\text { the resource stock. }\end{array}$ & $\begin{array}{l}\text { Two rounds later they decided to deplete the } \\
\text { resource stock before the experimenters would end } \\
\text { the game. }\end{array}$ & Yes \\
\hline
\end{tabular}




\begin{tabular}{|c|c|c|c|c|c|c|c|c|c|c|c|}
\hline ULT06 & 70 & 4 & Yes & Yes & No & No & No & Yes & -- & -- & -- \\
\hline $\mathrm{ULT} 7^{+}$ & 71 & 4 & No & No & $\begin{array}{l}\text { Yes, in } \\
\text { round } 1\end{array}$ & $\begin{array}{l}\text { Yes, in } \\
\text { round } 2\end{array}$ & No & No & $\begin{array}{l}\text { One subject did not take part in deciding on group } \\
\text { agreements, this subject made the group cross the } \\
\text { threshold. }\end{array}$ & $\begin{array}{l}\text { Trust eroded, long discussion on collaboration, trust, } \\
\text { individual gain. Group decided to take } 0 \text { resource } \\
\text { stock units in next round. All do so but one subject; } \\
\text { he/she depleted the stock (not the one that made the } \\
\text { group cross the threshold). }\end{array}$ & No \\
\hline ULT08 & 72 & 4 & No & No & $\begin{array}{l}\text { Yes, in } \\
\text { round } 13\end{array}$ & No & No & No & $\begin{array}{l}\text { Crossed the threshold on purpose, group wanted to } \\
\text { know which scenario they play. }\end{array}$ & -- & -- \\
\hline ULT09 & 73 & 3 & No & No & $\begin{array}{l}\text { Yes, in } \\
\text { round } 12\end{array}$ & No & No & No & & -- & -- \\
\hline ULT10" & 74 & 3 & Yes & Yes & $\begin{array}{l}\text { Yes, in } \\
\text { round } 5\end{array}$ & $\begin{array}{l}\text { Yes, in } \\
\text { round } 9^{\S}\end{array}$ & No & Yes & $\begin{array}{l}\text { Crossed the threshold on purpose while slowly } \\
\text { reduce the resource stock. }\end{array}$ & $\begin{array}{l}\text { Decided to deplete the resource stock four rounds } \\
\text { after they crossed the threshold since they believed } \\
\text { the game would end before they can bring back the } \\
\text { stock to a higher regeneration rate. }\end{array}$ & Yes \\
\hline ULT11 & 75 & 3 & No & No & $\begin{array}{l}\text { Yes, in } \\
\text { round } 8\end{array}$ & $\begin{array}{l}\text { Yes, in } \\
\text { round } 13^{\S}\end{array}$ & No & No & One subject refused to cooperate. & $\begin{array}{l}\text { First group agreement happened in round } 13 \text {, when } \\
\text { they decided to end the game. }\end{array}$ & No \\
\hline ULT12" & 76 & 3 & Yes & Yes & No & No & Yes & Yes & -- & -- & -- \\
\hline ULT13 & 77 & 3 & No & No & No & No & Yes & No & -- & -- & -- \\
\hline ULT14 & 78 & 4 & No & No & No & $\begin{array}{l}\text { Yes, in } \\
\text { round } 12^{\S}\end{array}$ & No & No & -- & Due to believe that game would end soon. & Yes \\
\hline ULT15 & 79 & 3 & No & No & $\begin{array}{l}\text { Yes, in } \\
\text { round } 14\end{array}$ & No & No & No & $\begin{array}{l}\text { Crossed the threshold on purpose, group wanted to } \\
\text { know which scenario they play. }\end{array}$ & -- & -- \\
\hline ULT16 & 80 & 4 & Yes & No & No & No & No & Yes & -- & -- & -- \\
\hline ULT17 & 81 & 4 & No & No & No & No & Yes & Yes & -- & -- & -- \\
\hline ULT18" & 82 & 4 & Yes & Yes & No & No & No & Yes & -- & -- & -- \\
\hline ULT19 & 83 & 4 & Yes & No & No & No & No & Yes & -- & -- & -- \\
\hline ULT20 & 84 & 4 & No & No & No & No & No & Yes & -- & -- & -- \\
\hline
\end{tabular}

Note: Expl. means exploitation. EOG means end of game effect, i.e. group ended the game due to believe that experimenters would end it soon. Note that a group that crossed the potential threshold and depleted the resource stock within the same round was not classified as a group that crossed the potential threshold.

${ }^{\dagger}$ These groups played scenario B.

${ }^{\ddagger}$ These groups reversed the regime shift, i.e. they rebuilt the resource stock to the higher regeneration rate.

${ }^{\S}$ These groups depleted the resource stock in cooperation.

IThese groups played less than 14 rounds (CT02 and CT04 played 12 rounds and the other groups played 13 rounds) due to time restrictions.

"These groups shared the harvest equally in each round throughout the entire game. 


\section{Literature cited}

D’Agostino, R. B., W. Chase, and A. Belanger. 1988. The Appropriateness of Some Common Procedures for Testing the Equality of Two Independent Binomial Populations. The American Statistician 42(3):198-202.

Henrich, J., S. J. Heine, and A. Norenzayan. 2010. The weirdest people in the world? The Behavioral and Brain Sciences 33:61-83.

Kanji, G. K. 1993. 100 Statistical Tests. SAGE Publications, London, UK.

Shapiro, S. S., and M. B. Wilk. 1965. An Analysis of Variance Test for Normality (Complete Samples). Biometrika 52:591-611. 
Appendix 4. Risk game.

This appendix contains the design, instructions and more detailed results (see Table A4.2) of a risk game that we employed in order to explore the risk preferences of our experimental subjects. We provide specifications of how the four treatments we used differ (see also Table A4.1) and how these different treatments affect choices.

In the risk game, subjects got to choose individually between three paired lotteries (A and B), where B was more risky than A, i.e. had a wider payoff spread. The expected utility (payoff) of $\mathrm{A}$ and $\mathrm{B}$ was varied across the three choices by changing the probability levels. This game is based on the one by Holt and Laury (2002). We have shortened (three instead of originally ten choices) and modified it (framed it in terms of losing and investing resource stock units) to fit it to our experiment. Due to this simplification, please note that this task provides us only with information on whether or not our subjects are extremely risk-averse or extremely risk-seeking (because the intermediate probabilities are not observed).

In total, we collected 253 observations of which we could only use 214 due to the fact that some answers were inconsistent or difficult to interpret. We alternated between four treatments: 1) 'no loss, low stakes' (74 observations), 2) 'no loss, high stakes' (45 observations), 3) 'investment, low stakes' (42 observations) and 4) 'investment, high stakes' (53 observations). By comparing results from the first two treatments, we can deduce if stakes influence the level of risk aversion. In the latter two treatments, we asked our participants to give up some of their earnings from what they had earned during the experiment. We added these two latter treatments to see whether or not subjects were more averse to risk when losses were involved compared to when only potential gains were involved. We employed these four different treatments in order to explore whether or not low vs. high stakes and no investment vs. investment influence behavior, as predicted by prospect theory (Kahneman and Tversky 1979). It is important to note that the subjects always had the option of opting out of the risk game. The most important question was to assess the risk preferences of our subjects.

The instructions we provide below are the ones for the 'no loss, low stakes' treatment. The instructions of the other no loss treatment coincides with this one except for the amount of money one can win (see Table A4.1 for more detailed information). For the two investment treatments, the potential earnings coincide with the no loss treatments but additionally subjects need to invest money in order to take part in the game.

Instructions for the 'no loss, low stakes' risk game treatment:

\section{Participant no.}

You now have the chance to earn some extra resource units. The exact amount of these extra units depends on the choices you will make. Please note that you cannot lose any of your already earned resource units by participating in this exercise.

For the three questions below, we ask you to decide between two options. For each question please indicate whether you prefer option A or B. 
After you made your choices, one of the decisions will be picked through a random draw. The amount of extra earned resource units, which will be converted to SEK, depends therefore on the option you chose for each decision and chance.

1. Option A gives you SEK 15 (3 extra resource units) with a 10 percent chance or SEK 10 ( 2 extra resource units) with a 90 percent chance.

Option B gives you SEK 20 (4 extra resource units) with a 10 percent chance or SEK 5 (1 extra resource unit) with a 90 percent chance.

I choose option:

2. Option A gives you SEK 15 (3 extra resource units) with a 50 percent chance or SEK 10 ( 2 extra resource units) with a 50 percent chance.

Option B gives you SEK 20 (4 extra resource units) with a 50 percent chance or SEK 5 (1 extra resource unit) with a 50 percent chance.

I choose option:

3. Option A gives you SEK 15 ( 3 extra resource units) with a 90 percent chance or SEK 10 ( 2 extra resource units) with a 10 percent chance.

Option B gives you SEK 20 (4 extra resource units) with a 90 percent chance or SEK 5 (1 extra resource unit) with a 10 percent chance.

I choose option:

Table A4.1, on the next page, compares the four risk game treatments in terms of expected values and payoff differences. By means of this information, we can determine the risk preferences of our subjects. An extremely risk-averse subject, for example, makes the following choices: option A for all three decisions (independent of treatment) because the lottery is safer. 
Table A4.1. Comparison of the four risk game treatments in terms of expected values and payoff differences. Prob means probability.

Treatment 1: no loss, low takes

\begin{tabular}{cccccccccccc}
\hline \hline Option & & & \multicolumn{3}{c}{ A } & & & B ("risky" option) & $\begin{array}{c}\text { Expected } \\
\text { payoff } \\
\text { difference }\end{array}$ \\
\hline Decision & Prob & SEK & Prob & SEK & Expected value & Prob & SEK & Prob & SEK & Expected value & \\
1 & 0.1 & 15 & 0.9 & 10 & 10.5 & 0.1 & 20 & 0.9 & 5 & 6.5 & 4 \\
2 & 0.5 & 15 & 0.5 & 10 & 12.5 & 0.5 & 20 & 0.5 & 5 & 12.5 & 0 \\
3 & 0.9 & 15 & 0.1 & 10 & 14.5 & 0.9 & 20 & 0.1 & 5 & 18.5 & -4 \\
\hline
\end{tabular}

Treatment 2: no loss, high stakes

\begin{tabular}{|c|c|c|c|c|c|c|c|c|c|c|c|}
\hline \multirow{2}{*}{$\begin{array}{r}\text { Option } \\
\text { Decision }\end{array}$} & \multicolumn{5}{|c|}{ A } & \multicolumn{5}{|c|}{ B ("risky" option) } & \multirow{2}{*}{$\begin{array}{c}\text { Expected } \\
\text { payoff } \\
\text { difference }\end{array}$} \\
\hline & Prob & SEK & Prob & SEK & Expected value & Prob & SEK & Prob & SEK & Expected value & \\
\hline 1 & 0.1 & 60 & 0.9 & 40 & 42 & 0.1 & 80 & 0.9 & 20 & 26 & 16 \\
\hline 2 & 0.5 & 60 & 0.5 & 40 & 50 & 0.5 & 80 & 0.5 & 20 & 50 & 0 \\
\hline 3 & 0.9 & 60 & 0.1 & 40 & 58 & 0.9 & 80 & 0.1 & 20 & 74 & -16 \\
\hline
\end{tabular}

Treatment 3: investment (SEK 10), low stakes

\begin{tabular}{cccccccccccc}
\hline \hline Option & & \multicolumn{3}{c}{ A } & & & B ("risky" option) & $\begin{array}{c}\text { Expected } \\
\text { payoff } \\
\text { difference }\end{array}$ \\
\hline Decision & Prob & SEK & Prob & SEK & Expected value & Prob & SEK & Prob & SEK & Expected value & \\
1 & 0.1 & 15 & 0.9 & 10 & 10.5 & 0.1 & 20 & 0.9 & 5 & 6.5 & 4 \\
2 & 0.5 & 15 & 0.5 & 10 & 12.5 & 0.5 & 20 & 0.5 & 5 & 12.5 & 0 \\
3 & 0.9 & 15 & 0.1 & 10 & 14.5 & 0.9 & 20 & 0.1 & 5 & 18.5 & -4 \\
\hline
\end{tabular}

Treatment 4: investment (SEK 40), high stakes

\begin{tabular}{cccccccccccc}
\hline \hline Option & & \multicolumn{3}{c}{ A } & & & B ("risky" option) & $\begin{array}{c}\text { Expected } \\
\text { payoff } \\
\text { difference }\end{array}$ \\
\hline Decision & Prob & SEK & Prob & SEK & Expected value & Prob & SEK & Prob & SEK & Expected value & \\
1 & 0.1 & 60 & 0.9 & 40 & 42 & 0.1 & 80 & 0.9 & 20 & 26 & 16 \\
2 & 0.5 & 60 & 0.5 & 40 & 50 & 0.5 & 80 & 0.5 & 20 & 50 & 0 \\
3 & 0.9 & 60 & 0.1 & 40 & 58 & 0.9 & 80 & 0.1 & 20 & 74 & -16 \\
\hline
\end{tabular}

Table A4.2. Results of the risk game.

\begin{tabular}{lcccccccc}
\hline & \multicolumn{2}{c}{ Treatment 1 } & Treatment 2 & \multicolumn{2}{c}{ Treatment 3 } & \multicolumn{2}{c}{ Treatment 4 } \\
\hline & $\mathrm{N}$ & $\%$ & $\mathrm{~N}$ & $\%$ & $\mathrm{~N}$ & $\%$ & $\mathrm{~N}$ & $\%$ \\
Extremely risk-averse & 12 & 16 & 12 & 27 & 10 & 24 & 9 & 17 \\
Neither of both & 57 & 77 & 32 & 71 & 31 & 74 & 40 & 75 \\
Extremely risk-seeking & 5 & 7 & 1 & 2 & 1 & 2 & 4 & 8 \\
\hline N = number subjects. & & & & & & & &
\end{tabular}

$\mathrm{N}=$ number subjects. 


\section{Literature cited}

Holt, C. A., and S. K. Laury. 2002. Risk Aversion and Incentive Effects. The American Economic Review 92(5):1644-1655.

Kahneman, D., and A. Tversky. 1979. Prospect theory: An analysis of decision under risk. Econometrica 47:263-291. 
Appendix 5. Optimal claims.

Table A5.1. Optimal claims for each resource stock size under the assumption that each group member believes that the game will continue one more round with a high enough probability.

\begin{tabular}{|c|c|c|c|c|c|c|c|c|c|}
\hline \multicolumn{5}{|c|}{$\begin{array}{l}\text { Scenario A } \\
\text { (logistic type of resource dynamics, no threshold) }\end{array}$} & \multicolumn{5}{|c|}{$\begin{array}{l}\text { Scenario B } \\
\text { (resource dynamics with threshold) }\end{array}$} \\
\hline $\begin{array}{l}\text { Resource } \\
\text { stock } \\
\text { size }(x)\end{array}$ & $\begin{array}{l}\text { Reg. } \\
\text { rate }\end{array}$ & $\begin{array}{l}\text { Optimal } \\
\text { claim }\end{array}$ & $\begin{array}{l}\text { \# rounds } \\
\text { until } x= \\
34=R\end{array}$ & $\begin{array}{l}\text { Harvest } \\
\text { during } \mathrm{R}\end{array}$ & $\begin{array}{l}\text { Resource } \\
\text { stock } \\
\text { size (x) }\end{array}$ & $\begin{array}{l}\text { Reg. } \\
\text { rate }\end{array}$ & $\begin{array}{l}\text { Optimal } \\
\text { claim }\end{array}$ & $\begin{array}{l}\text { \# rounds } \\
\text { until } x= \\
34=\mathrm{R}\end{array}$ & $\begin{array}{l}\text { Harvest } \\
\text { during } \\
\mathrm{R}\end{array}$ \\
\hline 50 & 0 & 25 & 1 & 25 & 50 & 0 & 25 & 1 & 25 \\
\hline 49 & 1 & 24 & 1 & 24 & 49 & 1 & 24 & 1 & 24 \\
\hline 48 & 1 & 23 & 1 & 23 & 48 & 1 & 23 & 1 & 23 \\
\hline 47 & 1 & 22 & 1 & 22 & 47 & 1 & 22 & 1 & 22 \\
\hline 46 & 1 & 21 & 1 & 21 & 46 & 1 & 21 & 1 & 21 \\
\hline 45 & 1 & 20 & 1 & 20 & 45 & 1 & 20 & 1 & 20 \\
\hline 44 & 3 & 19 & 1 & 19 & 44 & 3 & 19 & 1 & 19 \\
\hline 43 & 3 & 18 & 1 & 18 & 43 & 3 & 18 & 1 & 18 \\
\hline 42 & 3 & 17 & 1 & 17 & 42 & 3 & 17 & 1 & 17 \\
\hline 41 & 3 & 16 & 1 & 16 & 41 & 3 & 16 & 1 & 16 \\
\hline 40 & 3 & 15 & 1 & 15 & 40 & 3 & 15 & 1 & 15 \\
\hline 39 & 5 & 14 & 1 & 14 & 39 & 5 & 14 & 1 & 14 \\
\hline 38 & 5 & 13 & 1 & 13 & 38 & 5 & 13 & 1 & 13 \\
\hline 37 & 5 & 12 & 1 & 12 & 37 & 5 & 12 & 1 & 12 \\
\hline 36 & 5 & 11 & 1 & 11 & 36 & 5 & 11 & 1 & 11 \\
\hline 35 & 5 & 10 & 1 & 10 & 35 & 5 & 10 & 1 & 10 \\
\hline 34 & 7 & 9 & 1 & 9 & 34 & 7 & 9 & 1 & 9 \\
\hline 33 & 7 & 8 & 1 & 8 & 33 & 7 & 8 & 1 & 8 \\
\hline 32 & 7 & 7 & 1 & 7 & 32 & 7 & 7 & 1 & 7 \\
\hline 31 & 7 & 6 & 1 & 6 & 31 & 7 & 6 & 1 & 6 \\
\hline 30 & 7 & 5 & 1 & 5 & 30 & 7 & 5 & 1 & 5 \\
\hline 29 & 9 & 4 & 1 & 4 & 29 & 9 & 4 & 1 & 4 \\
\hline 28 & 9 & 3 & 1 & 3 & 28 & 9 & 3 & 1 & 3 \\
\hline 27 & 9 & 2 & 1 & 2 & 27 & 9 & 2 & 1 & 2 \\
\hline 26 & 9 & 1 & 1 & 1 & 26 & 9 & 1 & 1 & 1 \\
\hline 25 & 9 & 0 & 1 & 0 & 25 & 9 & 0 & 1 & 0 \\
\hline 24 & 7 & 4 & 2 & 6 & 24 & 7 alt. 1 & 4 alt. 0 & 2 & 6 alt. 0 \\
\hline 23 & 7 & 3 & 2 & 5 & 23 & 7 alt. 1 & 3 alt. 0 & 2 alt. 3 & 5 alt. 0 \\
\hline 22 & 7 & 2 & 2 & 4 & 22 & 7 alt. 1 & 2 alt. 0 & 2 alt. 4 & 4 alt. 0 \\
\hline 21 & 7 & 1 & 2 & 3 & 21 & 7 alt. 1 & 1 alt. 0 & 2 alt. 5 & 3 alt. 0 \\
\hline 20 & 7 & 0 & 2 & 2 & 20 & 7 alt. 1 & 0 & 2 alt. 6 & 2 alt. 0 \\
\hline 19 & 5 & 4 & 3 & 6 & 19 & 1 & 0 & 7 & 0 \\
\hline 18 & 5 & 3 & 3 & 5 & 18 & 1 & 0 & 8 & 0 \\
\hline
\end{tabular}




\begin{tabular}{llllllllll}
17 & 5 & 2 & 3 & 4 & 17 & 1 & 0 & 9 & 0 \\
16 & 5 & 1 & 3 & 3 & 16 & 1 & 0 & 10 & 0 \\
15 & 5 & 0 & 3 & 2 & 15 & 1 & 0 & 11 & 0 \\
14 & 3 & 2 & 4 & 4 & 14 & 2 & 0 & 11 & 0 \\
13 & 3 & 1 & 4 & 3 & 13 & 2 & 1 & 12 & 1 \\
12 & 3 & 0 & 4 & 2 & 12 & 2 & 0 & 12 & 0 \\
11 & 3 & 1 & 5 & 3 & 11 & 2 & 1 & 13 & 1 \\
10 & 3 & 0 & 5 & 3 & 10 & 2 & 0 & 13 & 0 \\
9 & 1 & 0 & 6 & 3 & 9 & 1 & 0 & 14 & 0 \\
8 & 1 & 0 & 7 & 3 & 8 & 1 & 0 & 15 & 0 \\
7 & 1 & 0 & 8 & 3 & 7 & 1 & 0 & 16 & 0 \\
6 & 1 & 0 & 9 & 3 & 6 & 1 & 0 & 17 & 0 \\
5 & 1 & 0 & 10 & 3 & 5 & 1 & 0 & 18 & 0 \\
\hline
\end{tabular}

Note that in scenario B, there is hysteresis between a resource stock size of 20 and 24 units. This implies that the regeneration rate depends on the most recent resource stock size. If the most recent stock size has been 20 units or below, the growth rate is one instead of seven and in this case, the optimal claim between 20 and 24 units should equal zero. Reg. stands for regeneration (second column). Optimal claim means sum of individual harvest decisions (third column). The fourth column (\# rounds until $x=34=\mathrm{R}$ ) indicates the number of consecutive rounds necessary to reach a resource stock of 34 units. The fifth column indicates the possible overall group harvest to reach a resource stock of 34 units. 
Appendix 6. Intuition underlying our hypotheses and proofs.

We rely on methods from repeated game theory and focus on the conditions under which different equilibrium outcomes can be sustained in the different treatments, i.e. we look at which resource stock sizes the group could possibly sustain for the entire game. Please see Lindahl et al. $(2012,2014)$ for a more detailed description of the game situation.

The subjects of our experiment play a dynamic CPR game with an indefinite time horizon (Carmichael 2005), i.e. they know that the game will end at some point but not exactly when. At each stage (round) of the game, each subject (player) $i$ in the group has, however, an individual perception about the likelihood whether or not the game will last another round (we can also call it a discount factor), which we denote $\delta_{i}$ (Fudenberg and Tirole 1998). These subjective probabilities will be crucial, which will become clearer as we go on.

Assume the following strategy for each player $i \in\{1, \ldots, n\}$, where $n$ is the total number of players in the group: a) In the first round, take $(50-x) / n$ units of the resource stock (to reach a stock size of $x$ ) and then, from the second round and onwards, take $\left(H_{x}\right) / n$ units ${ }^{1,2}$, where $H_{x}$ denotes the sustainable yield to keep stock size $x$. b) If in some round $t$ someone in the group deviates from this strategy (i.e. the new stock size is not $x$ ), then deplete the resource stock in the next round, $t+1$, i.e. claim (harvest) the entire resource stock. The maximum possible amount to claim is the current resource stock size (see Instructions in Appendix 1 for equation of individual payment calculation in case of depletion). Hence, for the deviating player in round $t$, the optimal deviation is to claim the entire resource stock $\left(x_{t}\right)$ in period $t$. Equation (A6.1) gives the payment (payoff) $P_{D C}$ of a player $i$ who deviates when all other players in the group play according to the strategy described above (i.e. cooperate), $h_{j t}$ represents the claimed harvest of player $j$ (who plays according to the strategy), where $j \neq i$.

$$
P_{D C}=\frac{x_{t}^{2}}{x_{t}+\sum_{j \in n, j \neq i} h_{j t}}
$$

If all players deplete the resource in the same round, the associated payoff for each player is $x_{t} / n$. Let $\delta_{i}$ denote the expected discounted value of one unit harvested capturing the subjective discount factor of player $i$ that the game will continue for one more round (in round $t$ ). Equation (A6.2) shows the total payoff, for player $i$ who follows the strategy for the entire game, given that all other players do so as well. The first term refers to the payoff, $P\left(n, \delta_{i}\right)$, in the first round (round 0 ) and the second term to the sum of the continuation payoffs in all subsequent rounds.

$$
P\left(n, \delta_{i}\right)=\frac{50-x}{n}+\sum_{t=1}^{\infty} \delta_{i}^{t} \frac{H_{x}}{n}
$$

The regeneration rate $H_{x}$ (i.e. the sustainable yield to keep stock size $x$ ) is, however, in the risk treatments not known with certainty for stock sizes $x \in\{10,11,12, \ldots 19\}$. We refer to the

\footnotetext{
${ }^{1}$ Note that we focus only on strategies supporting equal sharing equilibrium outcomes (if an equilibrium is sustained, it is based on equal shares of the resource stock size) because this is actually consistent with what we observed in the experiment. Whereas some of these equal sharing groups shared the harvest equally in each round, others used a rotating scheme to share the harvest equally over time.

${ }^{2}$ Note that in the risk treatments, for the range of resource stock sizes where the regeneration rates differ $(x \in\{10,11,12, \ldots 19\})$ the actual scenario played (scenario A (no threshold) or scenario B (threshold)) will be revealed after the first round because the regeneration rates differ.
} 
probability of a threshold (scenario B) as $\operatorname{Pr}(T)$ and to the probability of no threshold (scenario A) as $1-\operatorname{Pr}(T)$. Further, we denote regeneration rate when there is a threshold as $H_{x}^{T}$ and when there is no threshold as $H_{x}^{N T}$. Equation (A6.2) can then be rewritten:

$$
P\left(n, \delta_{i}\right)=\frac{50-x}{n}+\sum_{t=1}^{\infty} \delta_{i}^{t} E U\left(\frac{\operatorname{Pr}(T) H_{x}^{T}+(1-\operatorname{Pr}(T)) H_{x}^{N T}}{n}\right)
$$

Here, the expected utility $(E U)$ from the uncertain continuation payoff can belong to a riskneutral, averse or seeking player. From Equations (A6.1-A6.3), we can derive the necessary conditions for the outcome (a sustained stock size of $x$ ) to be sustainable as an equilibrium outcome: In the very first round, the payoff for a player who follows the described strategy for the entire game (given the other players do so as well) must be equal to or bigger than the payoff the player would get by deviating, i.e. depleting the resource stock, in the very first round. To save space, let $E U\left(H_{x} / n\right)$ denote $E U\left(\left(\operatorname{Pr}(T) H_{x}^{T}+(1-\operatorname{Pr}(T)) \mathrm{H}_{\mathrm{x}}^{\mathrm{NT}}\right) / n\right)$. In the very first round, no player deviates if Equation (A6.4) holds:

for all $i \in n$

$$
\begin{array}{r}
\frac{50-x}{n}+\sum_{t=1}^{\infty} \delta_{i}^{t} E U\left(\frac{H_{x}}{n}\right) \geq \frac{50^{2}}{50+\frac{50-x}{n}(n-1)} \Leftrightarrow \\
\frac{1}{1-\delta_{i}} n E U\left(\frac{H_{x}}{n}\right) \geq \frac{50^{2} n}{50+\frac{50-x}{n}(n-1)}-\left(50-x-n E U\left(\frac{H_{x}}{n}\right)\right) \Leftrightarrow \\
\frac{((100-x) n-(50-x)) n E U\left(\frac{H_{x}}{n}\right)}{50^{2} n^{2}-((100-x) n-(50-x))\left(50-x-n E U\left(\frac{H_{x}}{n}\right)\right)} \geq 1-\delta_{i} \Leftrightarrow \\
\delta_{i} \geq \hat{\delta}(x)=\frac{50^{2} n^{2}-((100-x) n-(50-x))(50-x)}{50^{2} n^{2}-((100-x) n-(50-x))\left(50-x-n E U\left(\frac{H_{\chi}}{n}\right)\right)}
\end{array}
$$

It is easy to verify that the critical discount factor $\hat{\delta}(x)$ of a risk averse player is for $x \in\{10,11,12, \ldots 19\}$ higher than that of a risk neutral player because $E U_{\text {averse }}\left(H_{x} / n\right)<$ $E U_{\text {neutral }}\left(H_{x} / n\right)$. Exactly how much higher will depend on the assumptions one makes on the level of risk aversion. (For a risk seeking player, the critical discount factor would be lower than that of a risk neutral player.)

In the subsequent rounds, because the players face the same game in each round, it is sufficient to check that the continuation payoff at time $t$ is equal to or larger than the deviation payoff. Note that in subsequent rounds, there is no longer any uncertainty about the regeneration rate because the true scenario will be revealed after the first round. Thus, the following needs to hold:

for all $i \in n$

$$
\begin{gathered}
\sum_{\tau=t}^{\infty} \delta_{i}^{(\tau-t)}\left(\frac{H_{x}}{n}\right) \geq \frac{\left(x+H_{x}\right)^{2}}{x+H_{x}+\frac{H_{x}(n-1)}{n}} \Leftrightarrow \\
\frac{1}{1-\delta_{i}} \geq \frac{\left(x+H_{x}\right)^{2} n^{2}}{\left(\left(x+H_{x}\right) n+H_{x}(n-1)\right) H_{x}} \Leftrightarrow \\
\frac{\left(\left(x+H_{x}\right) n+H_{x}(n-1)\right) H_{x}}{\left(x+H_{x}\right)^{2} n^{2}} \geq 1-\delta_{i} \Leftrightarrow \\
\delta_{i} \geq \hat{\delta}(x)=\frac{\left(x+H_{x}\right)^{2} n^{2}-\left(\left(x+2 H_{x}\right) n-H_{x}\right) H_{x}}{\left(x+H_{x}\right)^{2} n^{2}}
\end{gathered}
$$


For all parameters in our model, we have verified that if Equation (A6.4) holds, then Equation (A6.5) also holds (these calculations are available upon request). In Table A6.1, we present the critical discount factor, from Equation (A6.4), for all resource stock sizes for all four treatments. The risk treatments discount factors are based on risk neutral players.

The first observation we can make is that if all players in a group, for all rounds of the game, believe that the game will last another round with a high enough probability $\left(\delta_{i} \geq \hat{\delta}(x)\right)$, then each resource stock size of the game, $x \in\{5,6,7, \ldots, 50\}$, can be sustained as an equilibrium outcome. This critical value $(\hat{\delta}(x))$ varies with the regeneration rate of the resource stock. To stay at a given stock size, the group can harvest an amount exactly corresponding to the regeneration rate at that stock size. So if the group is at a given resource stock size, and if the regeneration rate is relatively high, the incentive to deviate and deplete the resource stock is low because the expected value of the sum of future payoffs is also relatively high (the group will be able to harvest a high amount of resource units each round). This means that the critical value of the subjective discount factor can be lower. From Lindahl et al., we know that the critical value $\hat{\delta}(x)$ will be the same in all treatments for those resource stock sizes where the regeneration rate is the same. Thus, it will be the same for stock sizes of $x \in\{5,6,7,8,9\} \cup$ $\{20,21,22, \ldots, 50\}$.

For resource stock sizes where the regeneration rates potentially differ, i.e. for $x \in\{10,11,12, \ldots, 19\}, \hat{\delta}(x)$ will be higher the more likely a threshold is (because the expected regeneration rate is lower). This is illustrated in Figure A6.1 (see also Table A6.1) where we have depicted these critical values for $x \in\{5,6,7,8,9\} \cup\{20,21,22, \ldots, 50\}$ and for all four treatments (for a game with 4 players).

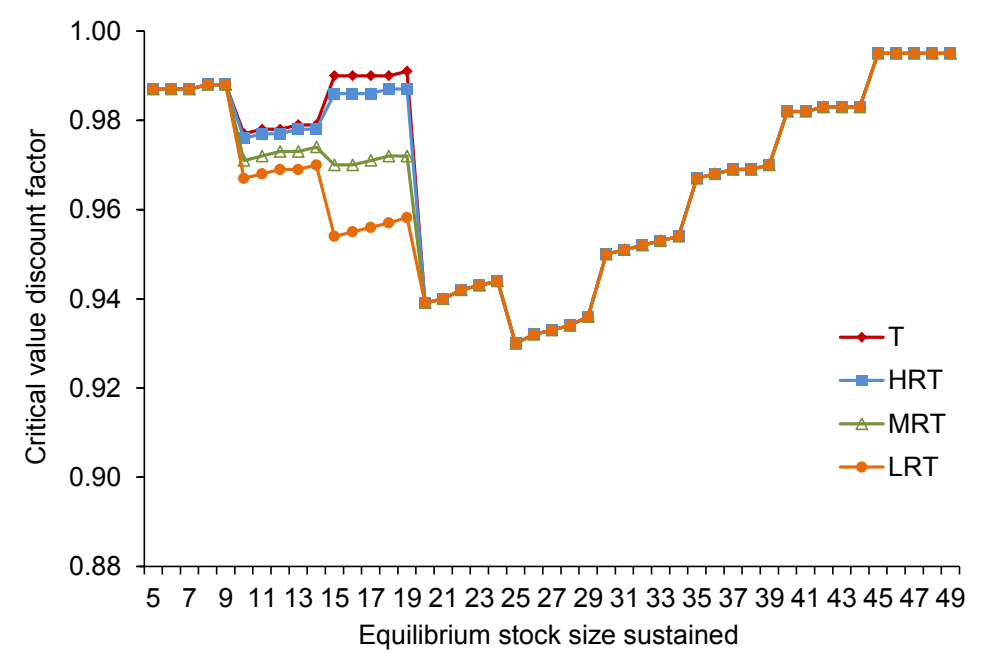

Fig. A6.1. Comparison of the critical values of the discount factor for the threshold (T), high-risk (HRT), medium-risk (MRT) and low-risk (LRT) treatment with four players.

Between stock sizes of 10 and 19, the incentive to deviate is higher and increasing with the probability of a threshold because the probability is high that the regeneration rate could become low. Thus, stock sizes between 10 and 19 (the range where the group would cross the threshold and where we find severe overexploitation according to the definition) are harder to sustain throughout the game the higher the probability of a threshold is. 
To be able to formulate hypotheses based on Table A6.1, we need to make some assumptions about the distribution of the discount factors of the players in the game. We denote this distribution $F\left(\delta_{i}\right)$. We need to assume, for example, that the range of the critical values for the discount factors, which is in the range between 0.930 and 0.995 , is a subset of the range of $F\left(\delta_{i}\right)$. Moreover, the distribution $F\left(\delta_{i}\right)$ is independent of treatment. Whereas the latter assumption is relatively straightforward, the former may need some elaboration. If the first assumption does not hold, i.e. if the discount factors of all players are below (above) the range of critical values, then no (all) equilibrium(s) can be sustained in the game and we would not see a distinction between the treatments.

Table A6.1. Critical discount factors for all resource stock sizes for all four treatments.

\begin{tabular}{|c|c|c|c|c|c|c|c|c|c|}
\hline $\begin{array}{l}\text { Stock } \\
\text { size }\end{array}$ & $\mathrm{T}$ & HRT & MRT & LRT & $\begin{array}{l}\text { Stock } \\
\text { size }\end{array}$ & $\mathrm{T}$ & HRT & MRT & LRT \\
\hline 5 & 0.987 & 0.987 & 0.987 & 0.987 & 28 & 0.934 & 0.934 & 0.934 & 0.934 \\
\hline 6 & 0.987 & 0.987 & 0.987 & 0.987 & 29 & 0.936 & 0.936 & 0.936 & 0.936 \\
\hline 7 & 0.987 & 0.987 & 0.987 & 0.987 & 30 & 0.950 & 0.950 & 0.950 & 0.950 \\
\hline 8 & 0.988 & 0.988 & 0.988 & 0.988 & 31 & 0.951 & 0.951 & 0.951 & 0.951 \\
\hline 9 & 0.988 & 0.988 & 0.988 & 0.988 & 32 & 0.952 & 0.952 & 0.952 & 0.952 \\
\hline 10 & 0.977 & 0.976 & 0.971 & 0.967 & 33 & 0.953 & 0.953 & 0.953 & 0.953 \\
\hline 11 & 0.978 & 0.977 & 0.972 & 0.968 & 34 & 0.954 & 0.954 & 0.954 & 0.954 \\
\hline 12 & 0.978 & 0.977 & 0.973 & 0.969 & 35 & 0.967 & 0.967 & 0.967 & 0.967 \\
\hline 13 & 0.979 & 0.978 & 0.973 & 0.969 & 36 & 0.968 & 0.968 & 0.968 & 0.968 \\
\hline 14 & 0.979 & 0.978 & 0.974 & 0.970 & 37 & 0.969 & 0.969 & 0.969 & 0.969 \\
\hline 15 & 0.990 & 0.986 & 0.970 & 0.954 & 38 & 0.969 & 0.969 & 0.969 & 0.969 \\
\hline 16 & 0.990 & 0.986 & 0.970 & 0.955 & 39 & 0.970 & 0.970 & 0.970 & 0.970 \\
\hline 17 & 0.990 & 0.986 & 0.971 & 0.956 & 40 & 0.982 & 0.982 & 0.982 & 0.982 \\
\hline 18 & 0.990 & 0.987 & 0.972 & 0.957 & 41 & 0.982 & 0.982 & 0.982 & 0.982 \\
\hline 19 & 0.991 & 0.987 & 0.972 & 0.958 & 42 & 0.983 & 0.983 & 0.983 & 0.983 \\
\hline 20 & 0.939 & 0.939 & 0.939 & 0.939 & 43 & 0.983 & 0.983 & 0.983 & 0.983 \\
\hline 21 & 0.940 & 0.940 & 0.940 & 0.940 & 44 & 0.983 & 0.983 & 0.983 & 0.983 \\
\hline 22 & 0.942 & 0.942 & 0.942 & 0.942 & 45 & 0.995 & 0.995 & 0.995 & 0.995 \\
\hline 23 & 0.943 & 0.943 & 0.943 & 0.943 & 46 & 0.995 & 0.995 & 0.995 & 0.995 \\
\hline 24 & 0.944 & 0.944 & 0.944 & 0.944 & 47 & 0.995 & 0.995 & 0.995 & 0.995 \\
\hline 25 & 0.930 & 0.930 & 0.930 & 0.930 & 48 & 0.995 & 0.995 & 0.995 & 0.995 \\
\hline 26 & 0.932 & 0.932 & 0.932 & 0.932 & 49 & 0.995 & 0.995 & 0.995 & 0.995 \\
\hline 27 & 0.933 & 0.933 & 0.933 & 0.933 & & & & & \\
\hline
\end{tabular}

Note: T denotes threshold, HRT high-risk, MRT medium-risk and LRT low-risk treatment. The discount factors of the latter three treatments (risk treatments) are based on risk neutral players.

\section{Literature cited}

Carmichael, F. 2005. A Guide to Game Theory. Pearson Education Limited, Essex, UK. Fudenberg, D., and J. Tirole. 1998. Game Theory. MIT Press, Cambridge, MA, USA. Lindahl, T., A.-S. Crépin, and C. Schill. 2012. Managing resources with potential regime shifts: Using experiments to explore social-ecological linkages in common resource systems. Beijer Discussion Paper Series 232. 
Lindahl, T., A.-S. Crépin, and C. Schill. 2014. Potential disasters can turn the tragedy into success. Beijer Discussion Paper Series 244. 